Article

\title{
Potential Impacts of Assimilating Every-10-Minute Himawari-8 Satellite Radiance with the POD-4DEnVar Method
}

\author{
Jingnan Wang ${ }^{1} \mathbb{D}$, Lifeng Zhang ${ }^{2, *}$, Jiping Guan ${ }^{2}$, Xiaodong Wang ${ }^{1}$, Mingyang Zhang ${ }^{2}$ and Yuan Wang ${ }^{2} \mathbb{D}$ \\ 1 College of Computer, National University of Defense Technology, Changsha 410000, China; \\ wangjingnan17a@nudt.edu.cn (J.W.); xdwang@nudt.edu.cn (X.W.) \\ 2 College of Meteorology and Oceanography, National University of Defense Technology, \\ Changsha 410000, China; guanjiping@nudt.edu.cn (J.G.); zhangmingyang18@nudt.edu.cn (M.Z.); \\ wangyuan19@nudt.edu.cn (Y.W.) \\ * Correspondence: zhanglifeng@nudt.edu.cn
}

Citation: Wang, J.; Zhang, L.; Guan, J.; Wang, X.; Zhang, M.; Wang, Y. Potential Impacts of Assimilating Every-10-Minute Himawari-8 Satellite Radiance with the POD-4DEnVar Method. Remote Sens. 2021, 13, 3765. https://doi.org/ $10.3390 / \mathrm{rs} 13183765$

Academic Editor: Ka Lok Chan

Received: 25 August 2021

Accepted: 15 September 2021

Published: 20 September 2021

Publisher's Note: MDPI stays neutral with regard to jurisdictional claims in published maps and institutional affiliations.

Copyright: (c) 2021 by the authors. Licensee MDPI, Basel, Switzerland. This article is an open access article distributed under the terms and conditions of the Creative Commons Attribution (CC BY) license (https:// creativecommons.org/licenses/by/ $4.0 /)$.
Abstract: The Advanced Himawari Imager (AHI) onboard the Himawari-8 geostationary satellite provides continuous observations every $10 \mathrm{~min}$. This study investigates the assimilation of every-10min radiance from the AHI with the POD-4DEnVar method. Cloud detection is conducted in the $\mathrm{AHI}$ quality control procedure to remove cloudy and precipitation-affected observations. Historical samples and physical ensembles are combined to construct four-dimensional ensembles according to the observed frequency of the Himawari- 8 satellite. The purpose of this study was to test the potential impacts of assimilating high temporal resolution observations with POD-4DEnVar in a numerical weather prediction (NWP) system. Two parallel experiments were performed with and without Himawari-8 radiance assimilation during the entire month of July 2020. The results of the experiment with radiance assimilation show that it improves the analysis and forecast accuracy of geopotential, horizontal wind field and relative humidity compared to the experiment without radiance assimilation. Moreover, the equitable threat score (ETS) of 24-h accumulated precipitation shows that assimilating Himawari-8 radiance improves the rainfall forecast accuracy. Improvements were found in the structure, amplitude and location of the precipitation. In addition, the ETS of hourly accumulated precipitation indicates that assimilating high temporal resolution Himawari-8 radiance can improve the prediction of rapidly developed rainfall. Overall, assimilating every-10-min AHI radiance from Himawari-8 with POD-4DEnVar has positive impacts on NWP.

Keywords: data assimilation; Himawari-8 satellite radiance; POD-4DEnVar; numerical weather prediction

\section{Introduction}

The accuracy of weather forecasts has been greatly improved in recent decades, which can be credited mostly to the development of numerical weather prediction (NWP) [1]. With the development of numerical models, the accuracy of the initial conditions is extremely critical for the quality of NWP. With the growing number of observations, data assimilation has become an effective way to provide accurate initial conditions by combining the information between a numerical model and observations [2,3]. Currently, variational data assimilation and ensemble Kalman filter (EnKF) are the most widely used assimilation methods. Three-dimensional variational assimilation (3DVar) has been developed for many years, which has been used in many operational NWP centers [4]. However, 3DVar can only assimilate observations at a single analysis time, with static background error covariance [5,6]. Thus, advanced four-dimensional variational assimilation (4DVar) is proposed with strong constraint in a forecast model. The 4DVar can assimilate observations at multiple analysis times with the background error covariance evolving over the assimilation window with the tangent linear and adjoint model [7-10]. However, the background error covariance at the beginning of the assimilation window is still static, and the coding, maintenance and updating of the tangent linear and adjoint model are 
extremely difficult. Thus, some other methods such as EnKF have been proposed and applied for atmospheric and oceanic data assimilation [11]. In comparison, EnKF estimates the background error covariance by ensemble forecasts, so it is flow-dependent $[12,13]$. In addition, EnKF is much easier to implement if not developing a tangent linear and adjoint model [14], which has been applied in German and Canadian daily operational forecast systems [15]. However, EnKF also has disadvantages. EnKF lacks the strong constraint of the 4DVar model. What is more, the accuracy of EnKF is dependent on limited ensemble members. Thus, both variational (3/4DVar) and ensemble assimilation (EnKF) methods have their own advantages and disadvantages. To overcome their weaknesses and combine their strengths, ensemble variational assimilation methods are proposed, which can construct flow-dependent background error covariance with the constraint model and at low computational cost [16]. Great efforts have been made to make use of the ensemble variational assimilation methods, showing positive effects on NWP [9,17-21]. To simplify the implementation of four-dimensional ensemble variational assimilation methods (4DEnVar), some researchers put forward advanced methods, such as the Singular Value Decomposition (SVD)-based En4DVar method [22] and Dimension-Reduced Projection 4DVar (DPR-4DVar) [23], which avoid the development of a tangent linear and adjoint model. In 2008, Tian et al. [24] developed the Proper Orthogonal Decomposition (POD)-based four-dimensional ensemble variational assimilation method (POD-4DEnVar) POD-4DEnVar solves the final analysis by applying the POD technique to four-dimensional ensembles in the assimilation window, thus avoiding the tangent linear and adjoint model. The POD-4DEnVar method has been evaluated by the Lorenz96 model, observing system simulation experiments (OSSEs) and shallow water wave equation, and the results show that this method outperforms the 4DVar and EnKF methods with lower computational costs [25-27].

Satellite radiance has become an important component of data assimilation systems in NWP models. Satellite observations have better spatiotemporal coverage, especially where conventional observations such as surface station and radiosonde are rare [28]. A polar-orbit satellite can provide observations with global coverage in high spatial resolution, but it cannot generate continuous observations for a fixed regional area. Many studies have demonstrated that the assimilation of polar-orbit satellite radiance apparently improves NWP [29-36]. In comparison, a geostationary satellite can provide high temporal resolution observations, with continuous images for a fixed area. High temporal resolution observation is much more appropriately utilized with four-dimensional assimilation methods. In recent years, many works on the assimilation of geostationary satellite radiance have been conducted. For example, Zou et al. (2011) [37], Zhang et al. (2016) [38] and Qin et al. (2018) [39] assimilated radiance from Geostationary Operation Environmental Satellite (GOES) series, showing its positive impacts on weather forecasts. Szyndel et al. (2005) [40] and Stegel et al. (2009) [41] investigated the assimilation of the Spinning Enhanced Visible and InfraRed Imager (SEVIRI) from Meteosat-8. Wang et al. [42] demonstrated that the assimilation of future geostationary microwave sounder (GEOMS) radiances can improve typhoon forecasts. Furthermore, Himawari- 8 is seen as the new generation of geostationary satellites of Japan. The Advanced Himawari Imager (AHI) can provide images for a fixed area every 10 min [43]. Recently, many researchers have carried out assimilation experiments on the AHI of Himawari-8. Ma et al. [44] investigated the preliminary impact of assimilating Himawari-8 AHI radiance in the Gridpoint Statistical Interpolation (GSI) analysis system, indicating that assimilation reduces forecast errors of upper-tropospheric water vapor. Kazumori et al. [45] assimilated hourly Himawari-8 radiance with the 4DVar method, showing positive impacts on rainfall forecast. Wang et al. [46] assimilated Himawari-8 radiance by 3DVar cycling in the Weather Research and Forecasting (WRF) model data assimilation system (WRFDA), finding improvements in NWP. Sawada et al. (2019) [47] and Honda et al. (2018) [48] assimilated all-sky Himawari-8 radiances into mesoscale models to improve the prediction of heavy rainfall and tropical cyclones, respectively. However, past studies on Himawari-8 radiance assimilation were 
mainly based on traditional assimilation methods. As mentioned above, the advanced POD-4DEnVar method has been proven to have great potential to improve NWP. Moreover, it has been demonstrated that assimilating polar-orbit satellite radiance with the POD$4 \mathrm{DEnVar}$ method is beneficial for weather forecasts [49,50]. Thus, the purpose of this study was to assimilate every-10-min AHI radiance from the Himawari-8 geostationary satellite with the POD-4DEnVar method. The potential impacts of assimilating high temporal resolution Himawari-8 radiance were evaluated through a one-month experiment. The paper is structured as follows. First, the methodology used in this paper is described in Section 2, including the POD-4DEnVar algorithm, methods to construct four-dimensional ensemble samples and quality control procedures for Himawari-8 AHI. Second, the experiment design is shown in Section 3. Section 4 presents the main results of assimilating Himawari-8 AHI radiance and discussions on its impacts on analysis and forecasts. Finally, conclusions are given in Section 5.

\section{Methodology}

\subsection{POD-4DEnVar Algorithm}

The POD-4DEnVar method originates from the traditional 4DVar methodology. The cost function of the 4DVar is as follows:

$$
J(\mathbf{x})=\frac{1}{2}\left(\mathbf{x}-\mathbf{x}_{b}\right)^{T} \mathbf{B}^{-1}\left(\mathbf{x}-\mathbf{x}_{b}\right)+\frac{1}{2} \sum_{k=0}^{s-1}\left[\mathbf{y}_{k}^{o b s}-\boldsymbol{H}_{k}\left(\boldsymbol{M}_{t_{0} \rightarrow t_{k}}(\mathbf{x})\right)\right]^{T} \mathbf{R}_{k}^{-1}\left[\mathbf{y}_{k}^{o b s}-\boldsymbol{H}_{k}\left(\boldsymbol{M}_{t_{0} \rightarrow t_{k}}(\mathbf{x})\right)\right]
$$

where $\mathbf{x}$ and $\mathbf{x}_{b}$ represent the analysis and background field, respectively; $\mathbf{B}$ and $\mathbf{R}$ are the error covariances of background and observations, respectively. $s$ is the total number of observations in the assimilation window. $\mathbf{y}_{k}^{o b s}$ represents the observations at the analysis time $k, \boldsymbol{H}_{k}$ is the observation operator and $\boldsymbol{M}_{t_{0} \rightarrow t_{k}}$ is the integration of the forecast model from time $t_{0}$ to $t_{k}$.

$$
\mathbf{x}_{t_{k}}=\boldsymbol{M}_{t_{0} \rightarrow t_{k}}\left(\mathbf{x}_{t_{0}}\right)
$$

The incremental format of the 4 DVar cost function is as follows:

$$
J\left(\mathbf{x}^{\prime}\right)=\frac{1}{2}\left(\mathbf{x}^{\prime}\right)^{T} \mathbf{B}^{-1}\left(\mathbf{x}^{\prime}\right)+\frac{1}{2} \sum_{k=0}^{s-1}\left[\mathbf{y}_{k}^{\prime}\left(\mathbf{x}^{\prime}\right)-\left(\mathbf{y}_{k}^{o b s}\right)^{\prime}\right]^{T} \mathbf{R}_{k}^{-1}\left[\mathbf{y}_{k}^{\prime}\left(\mathbf{x}^{\prime}\right)-\left(\mathbf{y}_{k}^{o b s}\right)^{\prime}\right]
$$

where, $\mathbf{x}^{\prime}=\mathbf{x}-\mathbf{x}_{b}$ represents the analysis increments; $\mathbf{y}_{k}^{\prime}\left(\mathbf{x}^{\prime}\right)$ and $\left(\mathbf{y}_{k}^{\text {obs }}\right)^{\prime}$ are the observation increment and observation innovation at analysis time $k$, respectively. The POD-4DEnVar method applies the POD technique to an ensemble sample, so the background error covariance can also be estimated by ensemble forecasts. Firstly, $N$ ensemble members $\left(\mathbf{x}_{1}, \mathbf{x}_{2}, \ldots, \mathbf{x}_{N}\right)$ are obtained by ensemble forecast at time $k$, which generate $N$ ensemble perturbations $\left(\mathbf{x}_{1}^{\prime}, \mathbf{x}_{2}^{\prime}, \ldots, \mathbf{x}_{N}^{\prime}\right)$ to the background field $\mathbf{x}_{b}$. The ensemble perturbations $\mathbf{x}_{i}{ }^{\prime}=\mathbf{x}_{i}-\mathbf{x}_{b}(\mathrm{i}=1,2, \ldots, \mathrm{N})$ make up the model perturbations (MPs) matrix $\mathbf{X}_{p}$. In the meantime, $N$ observation perturbations $\left(\mathbf{y}_{1}^{\prime}, \mathbf{y}_{2}^{\prime}, \ldots, \mathbf{y}_{N}^{\prime}\right)$ are constructed by the observation operator $H_{k}$, constructing the observation perturbation (OPs) matrix $\mathbf{Y}_{p}$.

Since the dimension of the observed variable space is much smaller than that of the model space [23], the POD decomposition is performed on the observation perturbation matrix $\mathbf{Y}_{p}$.

$$
\left(\mathbf{Y}^{p}\right)^{T}\left(\mathbf{Y}^{p}\right)=\mathbf{V} \boldsymbol{\Lambda}^{2} \mathbf{V}^{\mathrm{T}}
$$

where $\mathbf{V}$ and $\boldsymbol{\Lambda}$ are the decomposed eigenvector and eigenvalue, respectively. The OPs matrix $\mathbf{Y}_{p}$ and MPs matrix $\mathbf{X}_{p}$ are transformed as follows:

$$
\begin{aligned}
& \mathbf{P}_{y}=\mathbf{Y}^{p} \mathbf{V} \\
& \mathbf{P}_{x}=\mathbf{X}^{p} \mathbf{V},
\end{aligned}
$$


As a result, the POD transformed OPs and MPs are orthogonal and thus independent. At the same time, the error covariances of background $\mathbf{B}$ can be represented by the transformed MPs

$$
\mathbf{B}=\mathbf{P}_{x} \mathbf{P}_{x}^{T} /(N-1),
$$

The optimal solutions $\mathbf{x}^{\prime}$ and $\mathbf{y}^{\prime}$ can be expressed by the linear combinations of the POD-transformed MPs and OPs, where $\beta$ represents a set of coefficient vectors:

$$
\begin{aligned}
\mathbf{x}^{\prime} & =\mathbf{P}_{x} \boldsymbol{\beta}, \\
\mathbf{y}^{\prime} & =\mathbf{P}_{y} \boldsymbol{\beta},
\end{aligned}
$$

Thus, substituting (7)-(9) into the incremental format of 4 DVar (3), the control variable $\mathbf{x}^{\prime}$ is replaced by $\beta$ :

$$
J(\boldsymbol{\beta})=\frac{1}{2}(N-1) \cdot \boldsymbol{\beta}^{T} \mathbf{P}_{x}^{T}\left(\mathbf{P}_{x}^{T}\right)^{-1}\left(\mathbf{P}_{x}\right)^{-1} \mathbf{P}_{x} \boldsymbol{\beta}+\frac{1}{2}\left(\mathbf{P}_{y} \boldsymbol{\beta}-\left(\mathbf{y}^{o b s}\right)^{\prime}\right)^{T} \mathbf{R}^{-1}\left(\mathbf{P}_{y} \boldsymbol{\beta}-\left(\mathbf{y}^{o b s}\right)^{\prime}\right),
$$

After solving the optimal problem of (10) and substituting $\beta$ in (8), the optimal solution $\mathbf{x}^{\prime}$ can be simplified into the following form, in which $\mathbf{I}$ is the identity matrix.

$$
\mathbf{x}^{\prime}=\mathbf{P}_{x}\left[(N-1) \mathbf{I}+\mathbf{P}_{y}^{T} \mathbf{R}^{-1} \mathbf{P}_{y}\right]^{-1} \mathbf{P}_{y}^{T} \mathbf{R}^{-1}\left(\mathbf{y}^{o b s}\right)^{\prime},
$$

\subsection{Four-Dimensional Ensemble Sample Construction}

As is shown in the algorithm of the POD-4DEnVar method, the final optimal solution is represented by the POD-transformed model perturbation and observation perturbation matrix. Thus, the construction of ensemble samples plays an important role in the assimilation process. Theoretically, the ensemble size should be sufficiently large to represent the real uncertainty of the atmosphere. However, considering the computational cost and efficiency, limited ensembles have been widely used in assimilation [51]. Historical forecasts can well represent the uncertainty in forecast models with low computational cost [23]. Furthermore, the development of weather systems is directly related with physical processes. Thus, numerical simulations are extremely sensitive to the parameterization schemes in numerical models [52-55]. In this study, historical forecasts and physical ensembles are combined to construct the four-dimensional ensemble samples.

Since the real every-10-min Himawari-8 radiance is assimilated, the assimilation window was set to $1 \mathrm{~h}$, with the analysis time at the beginning in the assimilation window. Himawari-8 makes 7 observations every 10 min within $1 \mathrm{~h}$, so the assimilation window was divided into 7 sub-windows (slot 1 to 7 ). Figure 1 shows an example of the assimilation window at 1200 UTC, 1 July 2020. The central times of the 7 sub-windows are 1200, 1210, $1220,1230,1240,1250$ and 1300 UTC. The process of four-dimensional ensemble construction is shown in Figure 2. In order to combine a physical ensemble with historical forecasts, two integrations were made from the same initial time, but with different microphysics and cumulus parameterization schemes. First, using the Kessler scheme (microphysics, hereafter "mp6" as it is the 6th parameterization scheme in the WRF model) and the KainFritsch scheme (cumulus parameterization, hereafter "cu1"), a 3-h integration was made from 0600 to 0900 UTC. Then, the output at 0900 UTC was used as the initial condition to make a 6-h integration to 1500 UTC, during which the model output interval was set to 10 min according to Himawari- 8 observations. Here, a 4D sliding sampling strategy was applied into the model output. According to the assimilation window, every 7 results made up a sample, corresponding to 7 sub-windows. For example, ensemble 1 was $(0900,0910$, 0920, 0930, 0940, 0950, 1000 UTC). Thus, 31 ensemble samples were obtained through the first integration. In the meantime, the same procedure was carried out but with the New Thompson scheme (microphysics, hereafter "mp8") and the Betts-Miller-Janjic scheme (cumulus parameterization, hereafter "cu2"). Therefore, a total of 62 ensemble members were formed. 


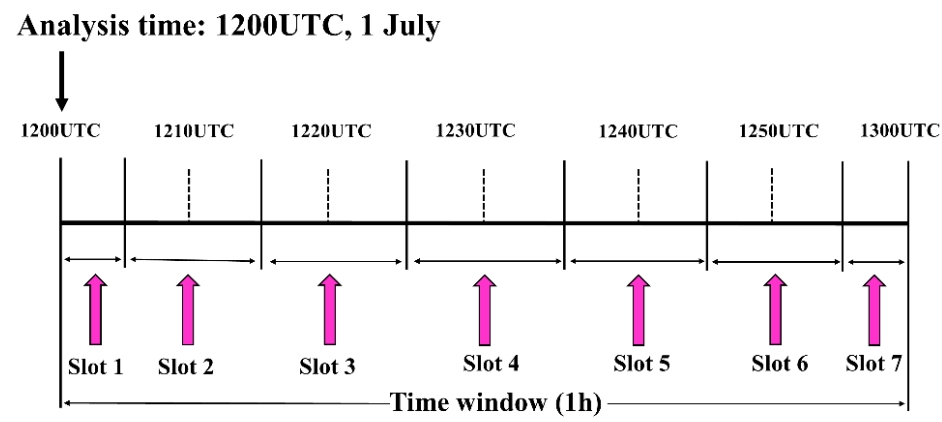

Figure 1. Design of the assimilation window and its sub-windows.

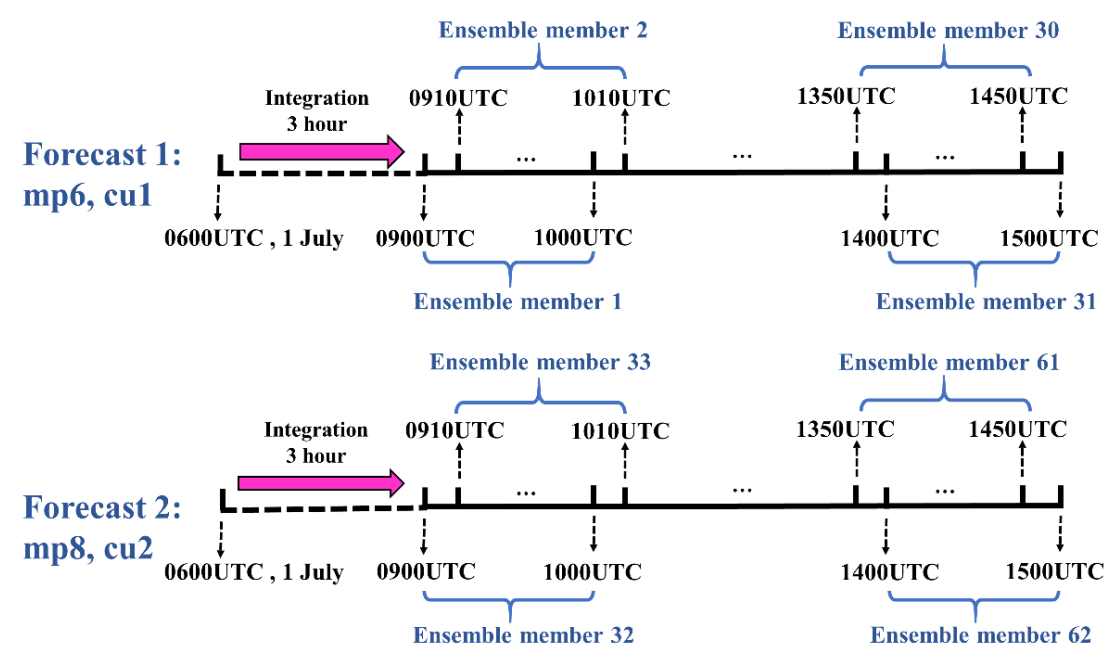

Figure 2. The flowchart of four-dimensional ensemble samples' construction.

\subsection{Himawari-8 Observations Quality Control}

Himawari-8 was successfully launched by the Japan Meteorological Agency (JMA) on 7 October 2014 and settled in geostationary orbit on 15 October 2015. It is located at $140.7^{\circ} \mathrm{E}$, covering the area from $80^{\circ} \mathrm{E}$ to $160^{\circ} \mathrm{W}$ and $60^{\circ} \mathrm{N}$ to $60^{\circ} \mathrm{S}$. The Advanced Himawari Imager (AHI) onboard Himawari-8 is comparable to the Advanced Baseline Imager (ABI) onboard GOES-R. The AHI has high spatial resolution, with the highest resolution of $0.5 \mathrm{~km}$ and others of 1, 2 and $5 \mathrm{~km}$. The AHI provides scans of the Full Disk (every $10 \mathrm{~min}$ ), Japan Area (every $2.5 \mathrm{~min}$ ), Target Area (every $2.5 \mathrm{~min}$ ), and two Landmark Areas (every $30 \mathrm{~s}$ ). The AHI has 16 observation bands, of which 3 are visible, 3 are near-infrared and 10 are infrared. Among the 16 bands, $8-10$ are water vapor absorption bands (with wavelengths of $6.2,6.9$ and $7.3 \mu \mathrm{m}$ ), which are sensitive to middle-to-upper tropospheric humidity [43]. Thus, bands 8-10 from Himawari-8 are assimilated in this study.

Quality control is the key element in satellite radiance assimilation in order to reduce the random error and systematic bias of radiance. The quality control procedures of AHI observations are as follows [46]: (1) gross check: removing those observations with a brightness temperature higher than $550 \mathrm{~K}$ or lower than $50 \mathrm{~K}$; (2) mixture surface type check: rejecting all channels over mixture surface type; (3) cloud liquid water check path check: rejecting those with cloud liquid water check path $\geq 0.2 \mathrm{~kg} / \mathrm{m}^{2}$; (4) relative departure check: removing observations whose bias-corrected innovation exceeds 3 times the observation error standard deviation; (5) absolute departure check: rejecting those whose bias-corrected innovation exceeds $8 \mathrm{~K}$. In addition, only clear-sky radiance is assimilated in this study; thus, cloud detection was required to discard cloud-affected pixels. The AHI level 2 cloud product was used to carry out cloud detection [56]. All the observations were classified into 11 types according to the cloud type, namely clear, cirrus (Ci), cirrostratus (Cs), deep convection, altocumulus (Ac), altostratus (As), nimbostratus (Ns), cumulus $(\mathrm{Cu})$, stratocumulus $(\mathrm{Sc})$, stratus (St) and others. Here, only "clear" observations were assimilated. 
Figure 3 presents the spatial distribution of observations and observations minus simulations before and after quality control of AHI channel 9 at 0000 UTC 20 July 2020. The simulated brightness temperature was calculated using Community Radiative Transfer Model (CRTM)-v2.2.3. The coverage of all observations before quality control is shown in Figure 3a, which includes both "good" and "bad" data. After quality control, the difference between the observed and simulated brightness temperature from background fields (OMB) is shown in Figure 3b. It can be seen that not all the observations pass the quality control, with "bad" data (about 65.5\%) rejected in this step. However, the differences between background and observations still reach up to $\pm 4 \mathrm{~K}$, with some OMBs being apparently larger than others. Figure $3 c$ shows the difference between the observed and simulated brightness temperature from analysis fields (OMAs). The OMA is clearly reduced for those with larger $\mathrm{OMB}$ values, especially those above $32^{\circ} \mathrm{N}$. To correct the systematic bias of radiance observations, the variational bias correction (VarBC) embedded in the WRFDA was applied in the POD-4DEnVar assimilation [57]. Figure 4 shows the scatter plots of the observations (OBS) and simulated brightness temperature from background (BAK) and analysis (ANA) fields. Figure $4 \mathrm{a}, \mathrm{b}$ compares the scatter plots when bias correction (BC) is carried out or not. Apparently, after the bias correction, the mean bias clearly reduced from 0.961 to 0.061 (by almost 93\%), and the root mean square error (RMSE) reduced from 1.589 to 1.268 (by almost 20\%). In comparison, ANA was in better agreement with OBS, with a reduction in mean bias to 0.051 (by almost 16\%), in standard deviation (STDV) to 0.832 (by almost 34\%) and in RMSE to 0.833 (by almost 34\%). The results indicate that quality control and bias correction are effective when assimilating Himawari-8 radiance.

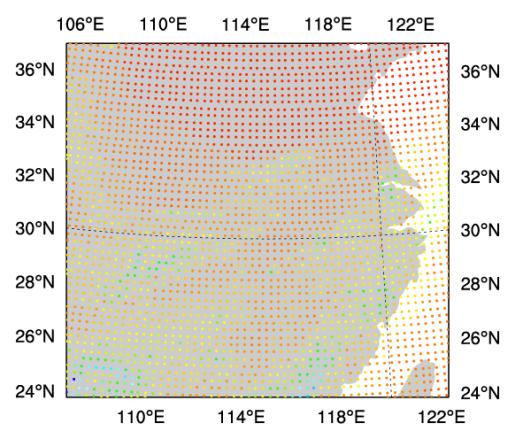

205210215220225230235240245250

(a)

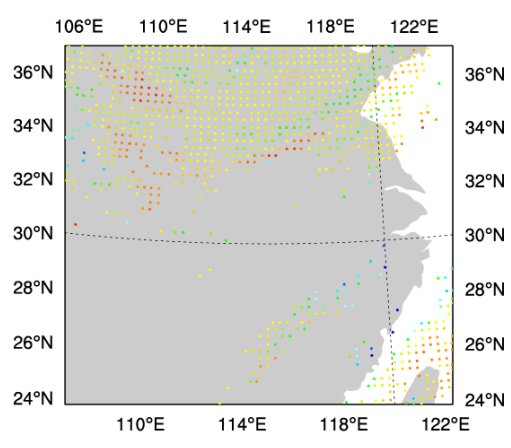

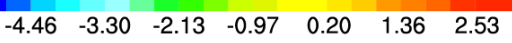

(b)

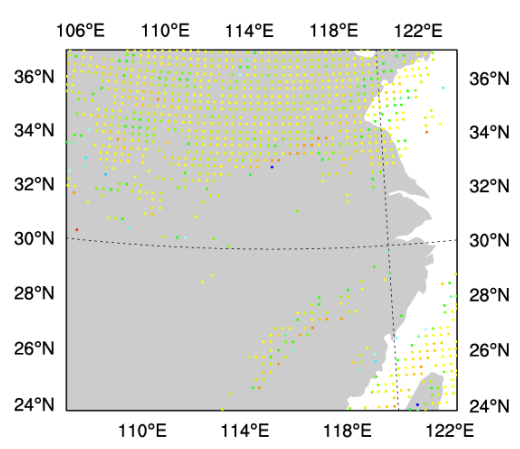

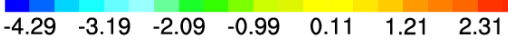

(c)

Figure 3. The Himawari- 8 brightness temperature (K) at 0000 UTC 20 July 2020 for (a) observations, (b) observations minus simulations from background (OMB) and (c) observations minus simulations from analysis (OMA). 


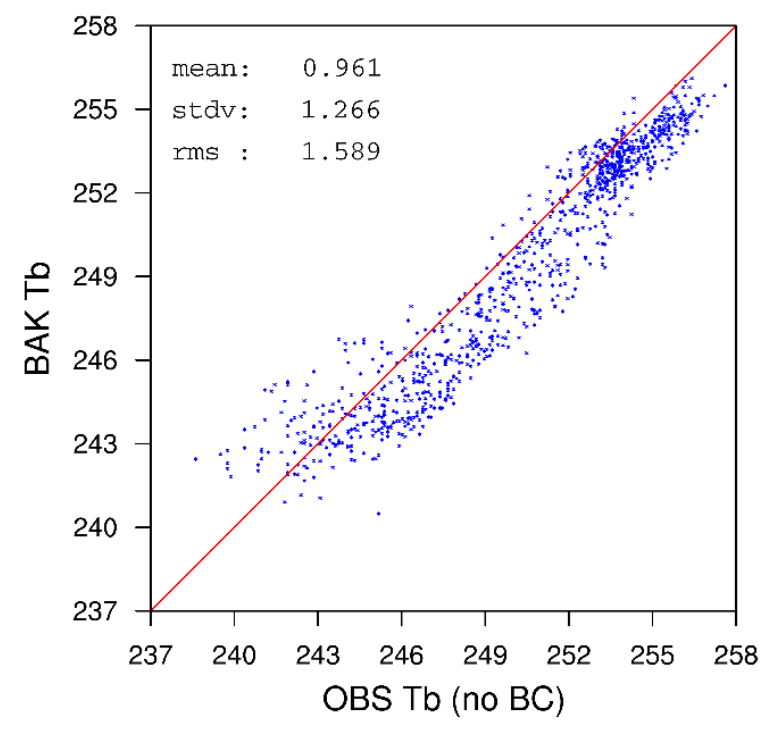

(a)

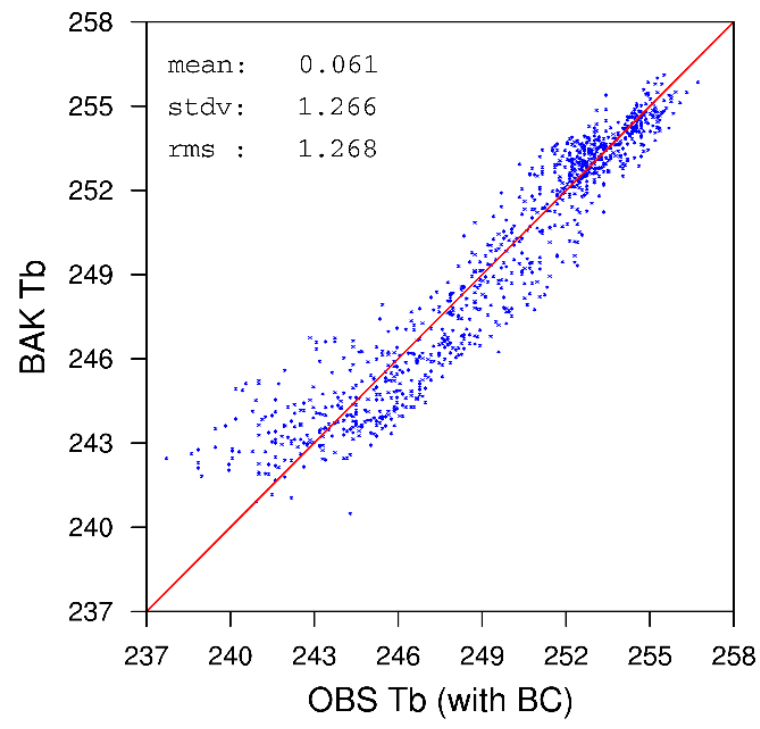

(b)

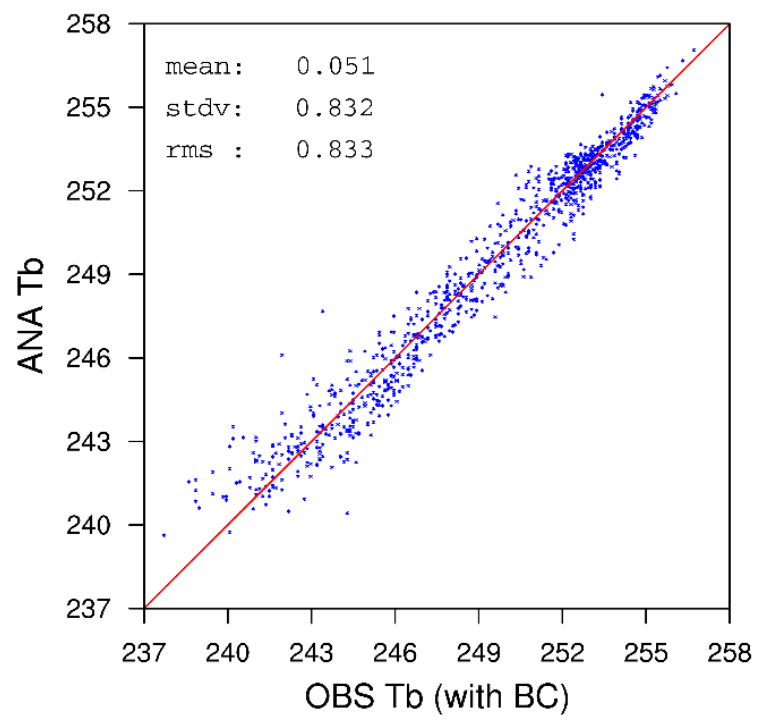

(c)

Figure 4. The scatterplots of observations against CRTM simulated brightness temperature (K) from (a) background without BC, (b) background with BC and (c) analysis with BC.

\section{Experiment Design}

This study employed the WRF-v3.9.1.1 model [58] to make ensemble forecasts and deterministic forecasts. The WRF model is configured with a two-nested domain, as shown in Figure 5. Clearly, the outer domain is in the coverage of Himawari- 8 observations mostly, and the inner domain is in full coverage of observations. The horizontal resolution of the outer domain is $15 \mathrm{~km}$, with $281 \times 281$ model grid points. The inner domain is of $5-\mathrm{km}$ horizontal grid spacing, with $322 \times 298$ model grid points mainly covering seven provinces of China. Both domains are configured with the model top of $50 \mathrm{hPa}$ and 35 vertical levels. The main physical parameterization schemes used in the WRF model are listed in Table 1. 


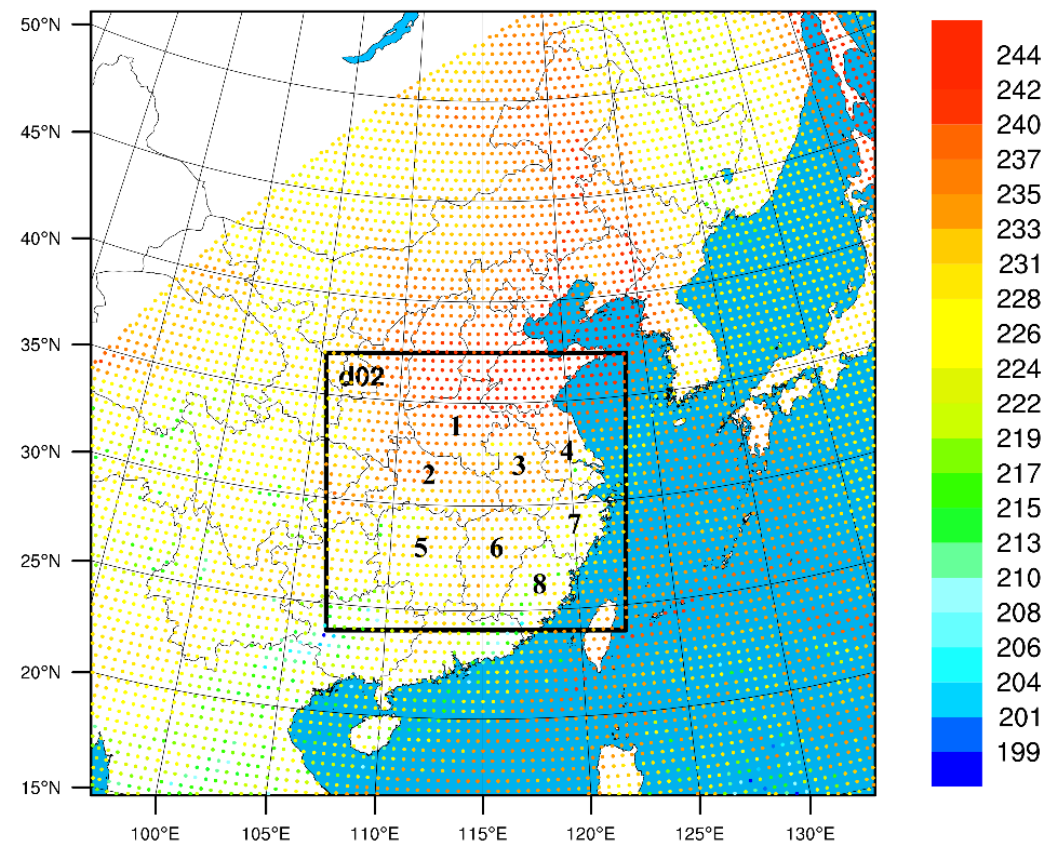

Figure 5. Two-nested domain design and observations covered in the domains. Color dots represent the brightness temperature from AHI channel 2 (units: K) at 0000 UTC 20 July 2020. The numbers represent the main provinces covered in domain 2 (1: Henan; 2: Hubei; 3: Anhui; 4: Jiangsu; 5: Hunan; 6: Jiangxi; 7: Zhejiang; 8: Fujian).

Table 1. Parameterization schemes.

\begin{tabular}{cc}
\hline Physics & Schemes \\
\hline Microphysics & Ensembles 1-31: Kessler scheme \\
Cumulus parameterization & Ensembles 32-62: New Thompson scheme \\
(not used in inner domain) & Ensembles 1-31: Kain-Fritsch scheme \\
Planetary boundary layer & Ensembles 32-62: Betts-Miller-Janjic scheme \\
Surface layer & Yonsei University scheme \\
Longwave radiation & Revised MM5 Monin-Obukhov scheme \\
Shortwave radiation & RRTM scheme \\
\hline
\end{tabular}

In order to investigate the impacts of assimilating Himawari- 8 radiance, two parallel experiments were designed, denoted as CTRL and HIM8. The CTRL experiment assimilated conventional observations in the inner domain [59], including radiosonde, synoptic observations, ships, airport reports, etc. The HIM8 experiment assimilated all the observations in CTRL plus every-10-min clear-sky radiance from Himawari-8 AHI channels 8, 9 and 10 in the inner domain. All the observations were thinned to $30 \mathrm{~km}$ in order to reduce the correlations [44-46]. The CRTM was used as the observation operator [60,61]. The WRF model utilizes National Centers for Environmental Prediction (NCEP) Final (FNL) Operational Model Global Tropospheric Analyses as the initial and lateral condition.

To evaluate the results statistically, a one-month analysis and forecast were conducted from 1 July to 31 July 2020. Figure 6 shows the schematic of the analysis and forecast configuration. Assimilation was performed at 0000 UTC each day. The assimilation window was set to $1 \mathrm{~h}$, with the analysis time at the beginning of the window. As mentioned above, the window was divided into seven sub-windows, corresponding to seven observations in an hour; Figure 6 shows an example from 0000 UTC 15 July. Ensemble forecasts were carried out before assimilation to provide ensemble samples. Furthermore, 24-h forecasts were made at 0000 UTC each day to evaluate the quality of forecasts. The evaluation was 
based on the average results, which is more valid statistically than just one single analysis and forecast.

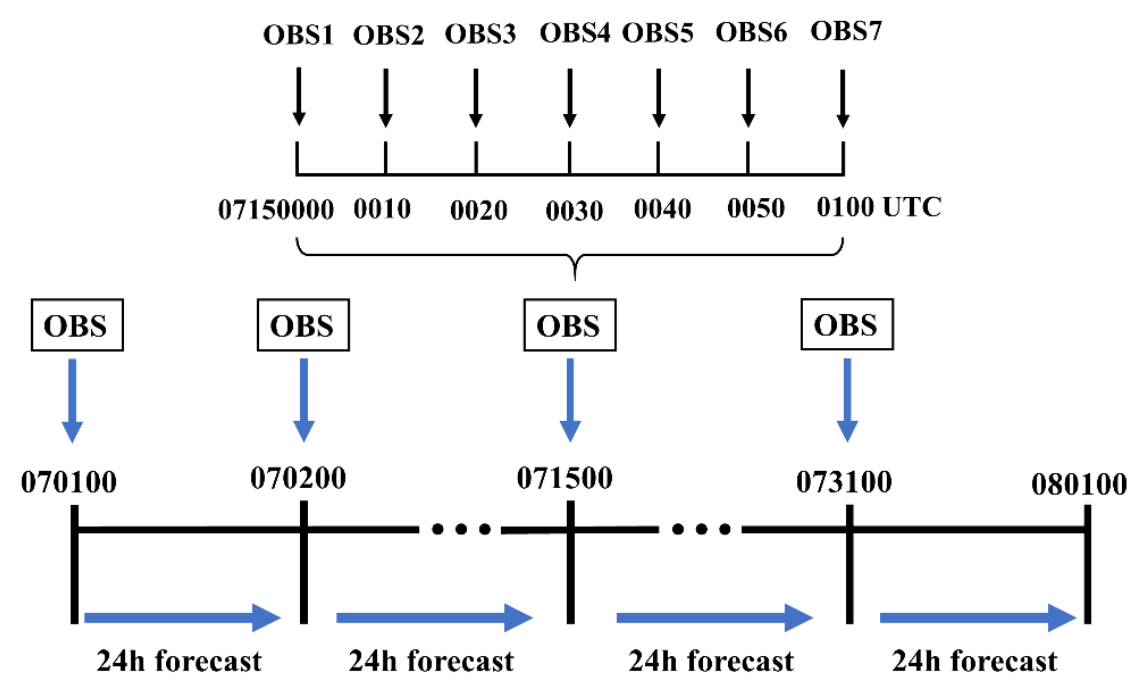

Figure 6. Schematic configuration of data assimilation and forecast experiments.

\section{Results and Discussion}

\subsection{RMSE Verification against ERA-5 Data}

In order to evaluate the impacts of assimilating Himawari-8 radiance, the fifth generation of the European Center for Medium Range Weather Forecasts (ECMWF) reanalysis (ERA-5) data was used as the "truth" [42,44,62-64].

Figure 7 displays the vertical profiles of average bias (dashed lines) and RMSE for geopotential, horizontal wind, temperature, water vapor mixing ratio and relative humidity from the analysis fields. The blue and red lines represent the CTRL and HIM8 experiments against ERA5, respectively. For geopotential (Figure 7a), the bias between CTRL and HIM8 is close under $850 \mathrm{hPa}$. HIM8 yields relatively lower bias from $850 \mathrm{hPa}$ to the top. The results of RMSE are similar to those of bias. The RMSE of HIM8 is clearly reduced above $850 \mathrm{hPa}$. For the U component of horizontal wind (Figure $7 \mathrm{~b}$ ), lower bias is found in HIM8 at upper levels. However, the RMSE is clearly improved from almost $900 \mathrm{hPa}$ to the top. Compared to $\mathrm{U}$, the improvement of the $\mathrm{V}$ component is much clearer (Figure 7c) when assimilating radiance. Lower bias in HIM8 was found, except at levels under $800 \mathrm{hPa}$. Especially for RMSE, an overall improvement in HIM8 was found from $900 \mathrm{hPa}$. For temperature (Figure 7d), small but positive impacts were found in HIM8 compared to the CTRL experiment, especially in middle and lower levels of RMSE. For the water vapor mixing ratio (Figure 7e), the impact of assimilation is smaller in the analysis field, and bias and RMSE are reduced in the middle and upper levels. However, the assimilation of Himawari-8 radiance has noticeable impacts on the relative humidity (Figure 7f). HIM8 shows little reduction in bias and RMSE in the middle and lower levels. The difference between the two experiments becomes clear above $500 \mathrm{hPa}$. It demonstrates that the relative humidity field of HIM8 is more favorable to ERA-5 data in the upper levels. In order to quantitively determine the difference between CTRL and HIM8, Table 2 displays the specific bias and RMSE values at different vertical levels of geopotential as an example. Statistically, the average improvement in bias is $6.44 \%$, with the largest improvement of $14.0 \%$ at $400 \mathrm{hPa}$. The average improvement in RMSE is $2.69 \%$, with the largest improvement of $5.84 \%$ at $100 \mathrm{hPa}$. 
Geopotential (m2/s2)

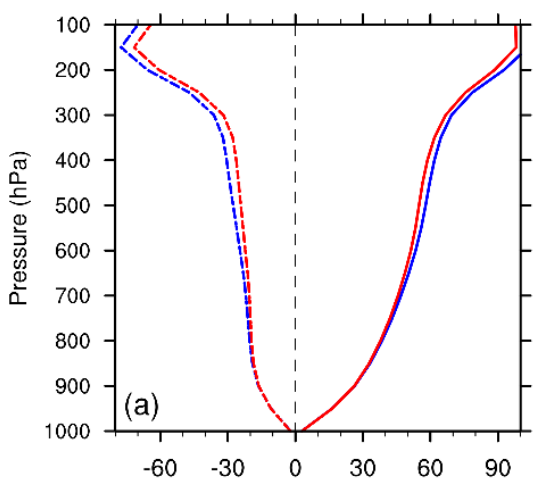

$\mathrm{T}(\mathrm{K})$

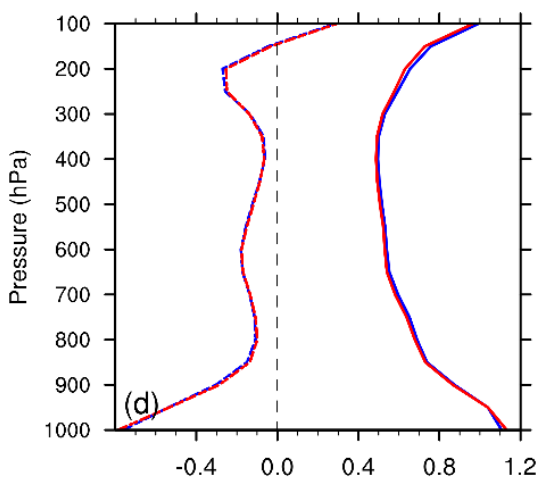

$\mathrm{U}(\mathrm{m} / \mathrm{s})$

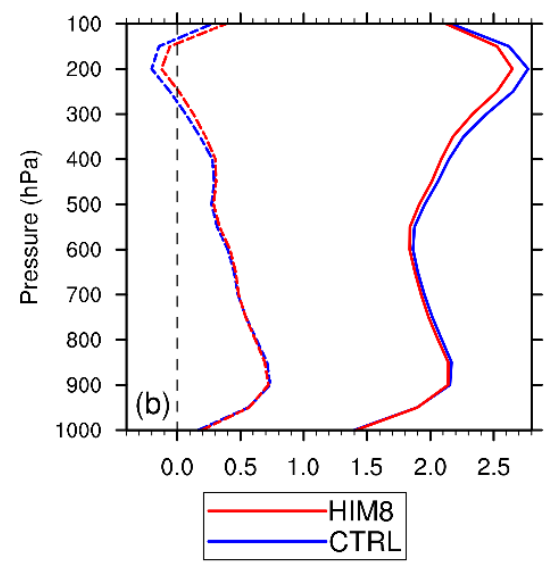

Qv $(g / \mathrm{kg})$

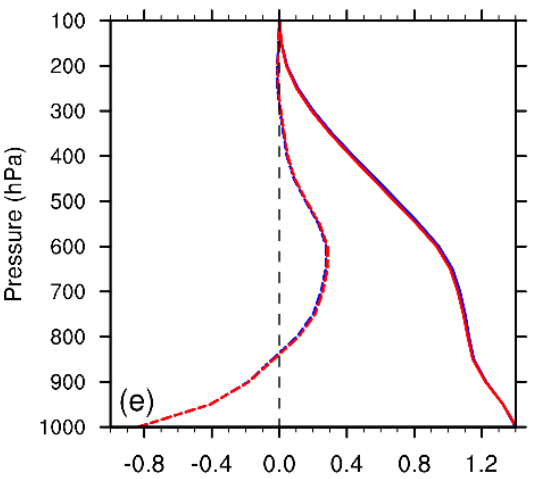

$\mathrm{V}(\mathrm{m} / \mathrm{s})$

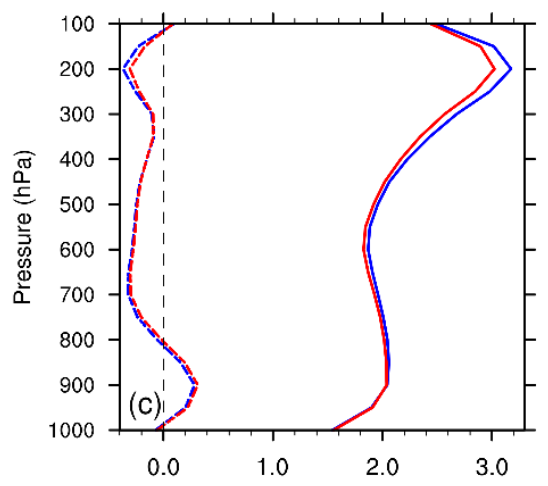

Relative Humidity (\%)

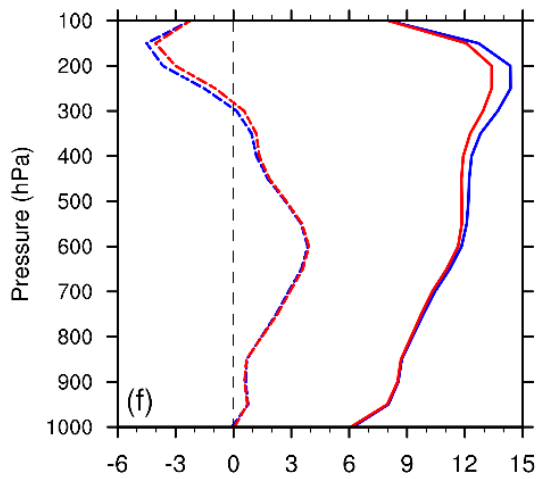

Figure 7. The vertical profiles of average bias (dash lines) and RMSE (solid lines) in CTRL (blue line) and HIM8 (red line) experiments for (a) geopotential, (b) U, (c) V, (d) temperature, (e) water vapor mixing ratio and (f) relative humidity from analysis fields.

Table 2. The geopotential analysis average bias and RMSE values at different heights.

\begin{tabular}{|c|c|c|c|c|c|c|c|c|c|c|c|c|c|}
\hline & Pressure (hPa) & 1000 & 950 & 900 & 850 & 800 & 700 & 600 & 500 & 400 & 300 & 200 & 100 \\
\hline \multirow{3}{*}{ Bias } & CRTL & -2.151 & -10.83 & -16.43 & -19.07 & -20.32 & -21.98 & -24.60 & -27.64 & -30.51 & -36.18 & -65.74 & -69.98 \\
\hline & & -2.198 & -10.87 & -16.26 & -18.57 & -19.48 & -20.41 & -22.23 & -24.21 & -26.24 & -31.96 & -60.59 & -64.28 \\
\hline & iprov & 4 & -0 & 1.0 & 2.61 & 4. & 7. & & & & & 7.8 & 8.16 \\
\hline \multirow{3}{*}{ RMSE } & & 2.8 & 16.32 & 26.34 & 33.16 & 38.48 & 46.91 & 53.43 & 57.86 & 61.76 & 69.36 & 92.69 & 103.8 \\
\hline & HIM8 & 2.914 & 16.38 & 26.22 & 32.79 & 37.83 & 45.59 & 51.31 & 54.94 & 58.66 & 66.75 & 88.53 & 97.79 \\
\hline & Improvement (\%) & -1.74 & -0.33 & 0.45 & 1.13 & 1.69 & 2.81 & 3.97 & 5.06 & 5.01 & 3.76 & 4.49 & 5.84 \\
\hline
\end{tabular}

Figure 8 displays the vertical profiles of average bias and RMSE from 24-h forecasts. The improvement of geopotential (Figure 8a) is much clearer when a 24-h forecast is conducted. The bias decreased from 700 to $100 \mathrm{hPa}$ in HIM8. The same improvement can also be found in RMSE, which decreased from 800 to $100 \mathrm{hPa}$. A relatively slight reduction was found for the $\mathrm{U}$ and $\mathrm{V}$ components of wind (Figure $8 \mathrm{~b}, \mathrm{c}$ ). The bias from CTRL and HIM8 was close for $U$ and V, with little improvement in the middle levels. Positive impacts were found in RMSE for U and V. The RMSE in HIM8 is reduced from 900 to almost $100 \mathrm{hPa}$ for $\mathrm{U}$, and the reduction is much more apparent than $\mathrm{V}$. For temperature (Figure 8d), lower bias appears between 800 and $600 \mathrm{hPa}$ in HIM8 compared to CTRL. A similar reduction was found in RMSE, with lower RMSE in the middle and lower levels. The impact of assimilation on water vapor mixing ratio forecast (Figure 8e) is slight and mainly in the middle levels. For relative humidity (Figure 8f), the difference between the two experiments is not as clear as in the analysis field. The main improvements were found between 800 and $600 \mathrm{hPa}$. The specific bias and RMSE values of 24-h geopotential forecasts are taken as an example to be analyzed quantitatively in Table 3. Compared 
to CTRL, the average of forecast bias is reduced by $7.57 \%$, with the largest reduction of $68.71 \%$ at $300 \mathrm{hPa}$. Meanwhile, the average forecast RMSE is reduced by $4.23 \%$, with the largest reduction by $7.03 \%$ at $400 \mathrm{hPa}$. Overall, Himawari- 8 radiance assimilation with the POD-4DEnVar method shows a positive impact on the main meteorological elements' analysis and forecasts.
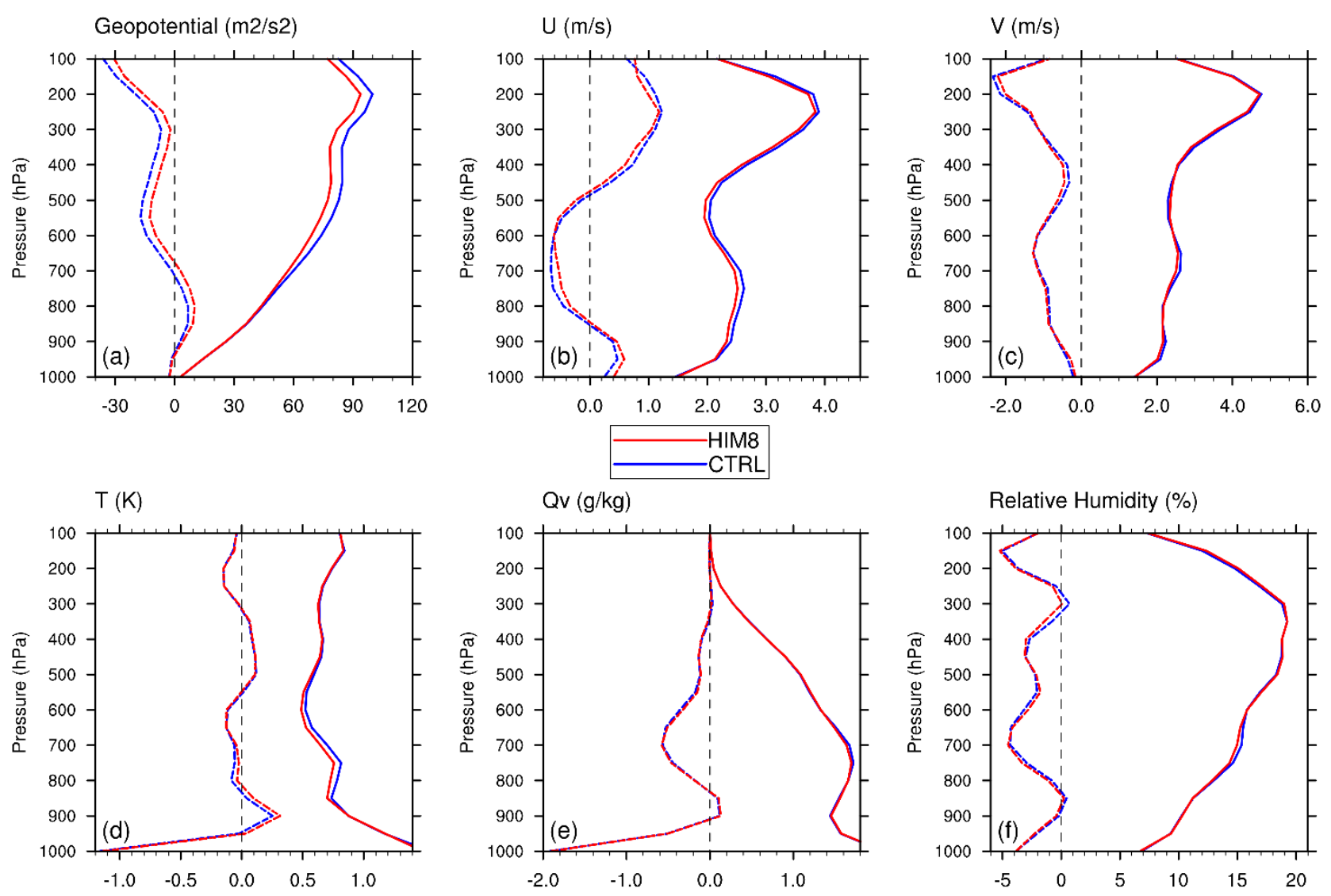

Figure 8. The vertical profiles of average bias (dash lines) and RMSE (solid lines) in CTRL (blue line) and HIM8 (red line) experiments for (a) geopotential, (b) $\mathrm{U},(\mathbf{c}) \mathrm{V},(\mathbf{d})$ temperature, (e) water vapor mixing ratio and (f) relative humidity from 24-h forecast fields.

Table 3. The geopotential 24-h forecast average bias and RMSE values at different heights.

\begin{tabular}{|c|c|c|c|c|c|c|c|c|c|c|c|c|c|}
\hline & Pressure (hPa) & 1000 & 950 & 900 & 850 & 800 & 700 & 600 & 500 & 400 & 300 & 200 & 100 \\
\hline \multirow{4}{*}{ Bias } & CRTL & -2.589 & -1.662 & 2.733 & 6.759 & 6.765 & -7.836 & -14.138 & -16.09 & -11.04 & -6.797 & -19.67 & -36.02 \\
\hline & & -2.554 & -1.169 & 4.118 & 9.224 & 10.14 & -3.353 & -9.498 & -11.57 & -6.490 & & -15.68 & -30.50 \\
\hline & Improvement (\%) & 1.36 & 29.65 & -50.64 & -36.45 & -49.93 & 57.20 & 32.82 & 28.07 & 41.26 & 68.71 & 20.29 & 15.34 \\
\hline & & & & & & & & & & & & 99.80 & 82.58 \\
\hline \multirow[t]{2}{*}{ RMSE } & & 2.913 & 14.06 & 25.82 & 36.06 & 43.68 & 57.18 & 68.93 & 77.27 & 78.57 & 81.87 & 93.81 & 77.09 \\
\hline & Improvement (\%) & 1.84 & 0.94 & 0.59 & 0.87 & 1.72 & 4.46 & 6.81 & 6.72 & 7.03 & 6.71 & 6.00 & 6.65 \\
\hline
\end{tabular}

\subsection{Impacts on Rainfall Forecasts}

Rainfall events usually have a great influence on people's daily life, even causing meteorological disasters. Thus, it is important that rainfall should be skillfully predicted by the numerical model. Thus, rainfall forecasting was used to further evaluate the performance of Himawari-8 radiance assimilation with the POD-4DEnVar method. The China Hourly Ground Station Precipitation merged with the Climate Prediction Center morphing precipitation products (CMORPH) was used for evaluation. During the onemonth experiments, three concentrated precipitation events in the inner domain were found, taking place on 5 July 6 July and 18 July 2020. The domain-averaged precipitation amount and its every-3-h growth are displayed in Figure 9. On 5 July (Figure 9a), the 
domain-averaged precipitation amount decreased until 1200 UTC, with a rapid decrease from 0400 to 0600 UTC. After 1200 UTC, the rainfall began to strengthen, especially at 2000 UTC when a quick intensification of rainfall was found. On 6 July (Figure 9b), there were two periods of negative 3-h growth from 0400 to 0700 UTC and from 1100 to 1900 UTC. The precipitation weakened quickly after 1200 UTC, reaching the weakest intensity at 1800 UTC. After that, the rainfall rapidly strengthened. On 18 July (Figure 9c), the precipitation was continuously strengthening after 0500 UTC. The largest increases were found at 1000 and 1800 UTC. After 2200 UTC, the amount of precipitation decreased slightly.

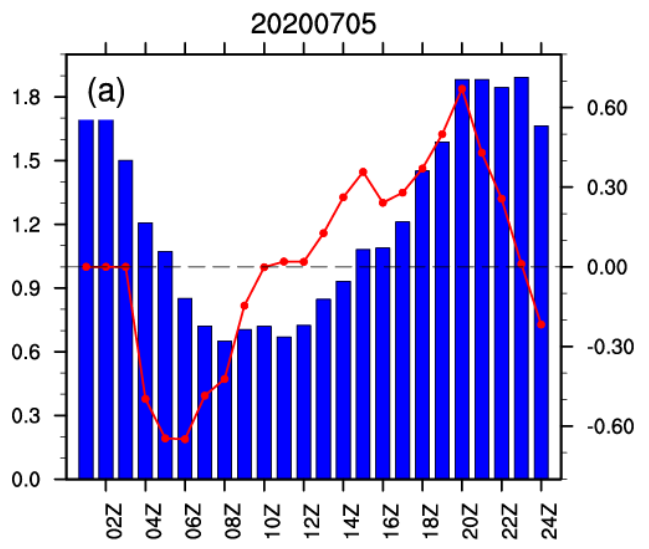

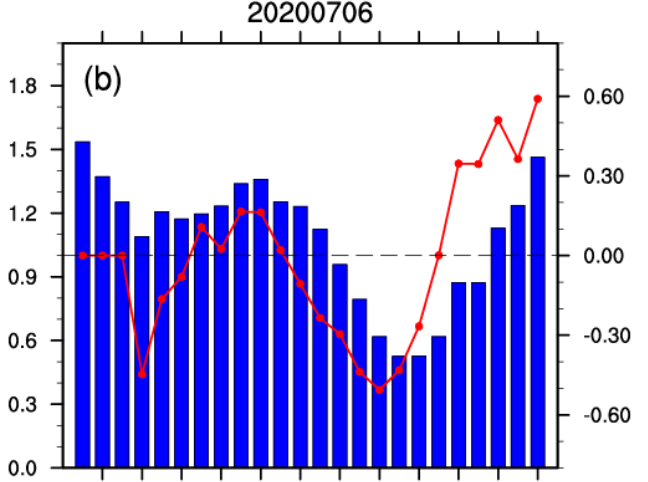

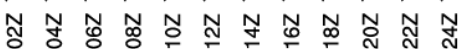

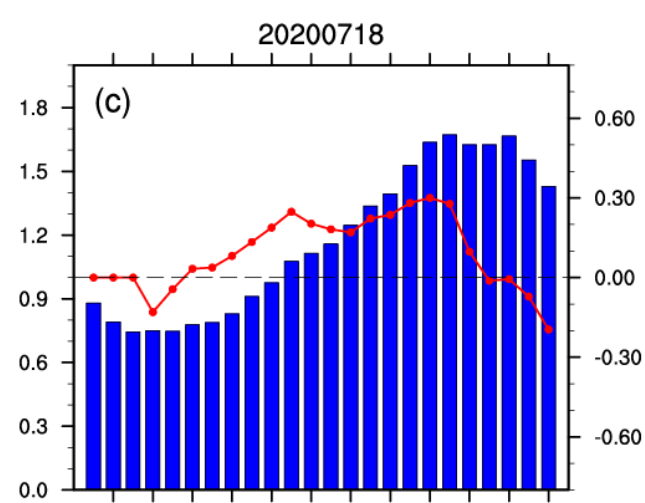

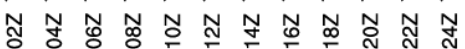

Figure 9. The evolution of hourly precipitation (box, left Y-axis with unit of $\mathrm{mm}$ ) and growth rate of precipitation every $3 \mathrm{~h}$ (solid line, right Y-axis) at different times (X-axis) on (a) 5 July (b) 6 July and (c) 18 July 2020.

Figure 10 shows the equitable threat score (ETS) of different thresholds for 24-h accumulated precipitation from 0000 to 2400 UTC. The ETS ranges between $-1 / 3$ and 1 , with negative or zero values indicating no skill and 1 indicating a perfect score [65]. It is seen that the ETS values generally decrease as the precipitation strengthens, indicating that the prediction skill of weaker rainfall is better than that of heavier rainfall, no matter for CTRL or HIM8. On 5 July (Figure 10a), positive impacts were found in HIM8 compared to CTRL, except for the $100 \mathrm{~mm}$ threshold. On average, the ETS of HIM8 increased by $1.74 \%$ compared to CTRL. On 6 July (Figure 10b), the ETS of HIM8 increased compared to CTRL, except for the 0.1 and $100 \mathrm{~mm}$ thresholds. The ETS of HIM8 relatively improved by $2.58 \%$ on average. On 18 July (Figure 10c), HIM8 yielded a higher ETS than CTRL generally, demonstrating that the assimilation of Himawari-8 radiance further enhanced the performance for the rainfall prediction on 18 July. The ETS of HIM8 improved by $3.68 \%$ on 18 July. On average, the ETS of 24-h accumulated precipitation improved by $2.67 \%$ over the three cases, demonstrating the positive impact of Himawari-8 radiance assimilation on rainfall forecasts. 

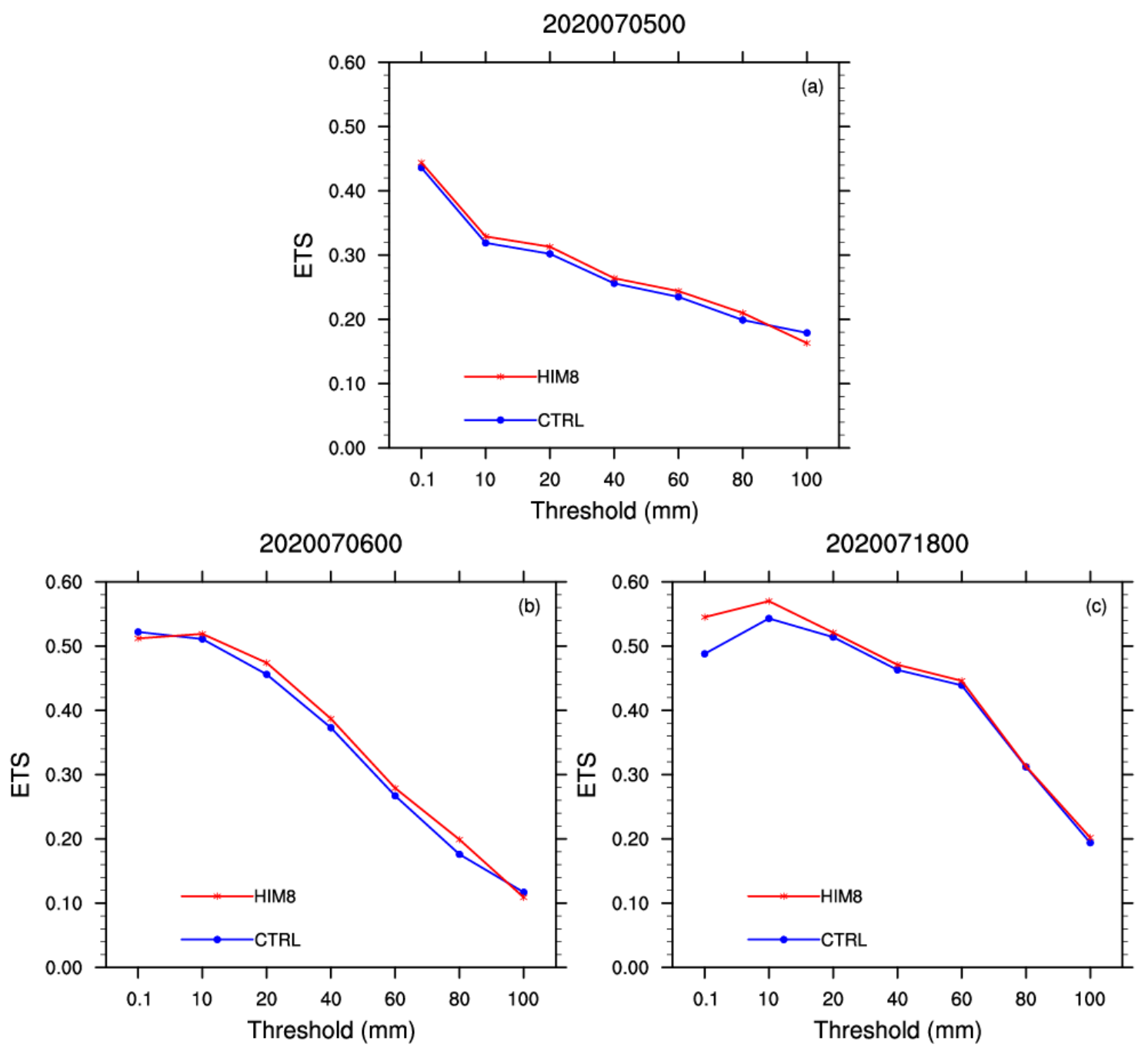

Figure 10. The ETS of 24-h accumulated precipitation initialized at (a) 0000 UTC on 5 July (b) 0000 UTC on 6 July and (c) 0000 UTC on 18 July 2020 for different thresholds.

To objectively and quantitatively verify the precipitation forecast, the Structure, Amplitude and Location (SAL) assessment method was adopted as the second verification method [66]. The A component measures the relative deviation of the domain-averaged quantitative precipitation forecasts. The L component is related to the location of precipitation, such as the displacement of the precipitation field's center of mass. The S component measures the predicted precipitation objects with observations, such as whether the objects are too large or too small. Perfect predictions are characterized by 0 for the $S, A$ and $L$ components, indicating that smaller absolute values yield better forecasts [66]. Figure 11 displays the SAL results of 24-h accumulated precipitation from the two experiments. On 5 July (Figure 11a,d,f), the S value in HIM8 was clearly closer to zero compared to CTRL, showing better precipitation structure prediction, especially for the $100 \mathrm{~mm}$ threshold. All the A values were negative for the three thresholds, indicating that the model underestimates the area-integrated precipitation. However, with radiance assimilation, lower absolute A values were obtained for all the thresholds, showing improvements in the amplitude prediction. For L, both experiments yielded small values for $0 \mathrm{~mm}$, indicating excellent performance in predicting the precipitation location. HIM8 yielded a slightly higher $\mathrm{L}$ value for $0 \mathrm{~mm}$ and a lower $\mathrm{L}$ value for 50 and $100 \mathrm{~mm}$. On 6 July (Figure 11b,e,h), HIM8 showed slightly larger structure errors than CRTL did for $0 \mathrm{~mm}$ but a clearly smaller structure error for $100 \mathrm{~mm}$. For amplitude, all the experiments overestimated the 24-h accumulated precipitation, but HIM8 had smaller errors in terms of amplitude. For location, 
smaller errors were found for HIM8 at 0 and $50 \mathrm{~mm}$. With the $100 \mathrm{~mm}$ threshold, HIM8 slightly overestimated the location more than CTRL did. For 18 July (Figure 11c,f,i), the structure of rainfall was better predicted in HIM8 for all thresholds. For amplitude, both experiments underestimated the precipitation intensity, with HIM8 showing smaller errors for all the thresholds. For location, similar to the results on 5 July the L values from both experiments for $0 \mathrm{~mm}$ were almost zero, indicating that the rainfall location was nearly perfectly predicted in both experiments. At the $50 \mathrm{~mm}$ threshold, the location error was clearly reduced in HIM8 compared to CTRL. The location errors of the two experiments were close at $100 \mathrm{~mm}$, showing little impact of radiance assimilation on location prediction. Overall, the SAL evaluation indicates that assimilating Himawari-8 radiance can improve the rainfall prediction from different aspects.
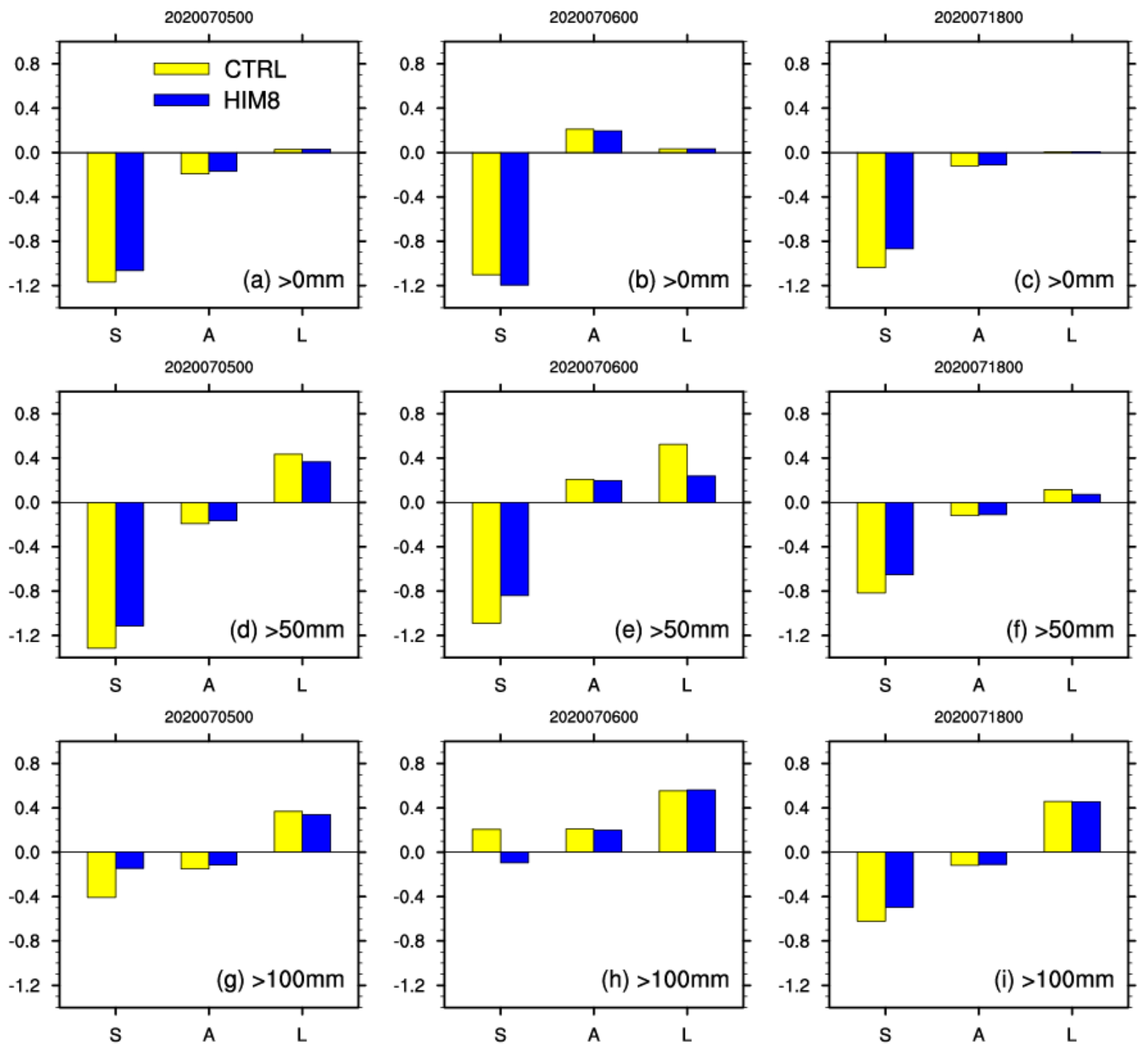

Figure 11. The SAL evaluation on 24-h accumulated precipitation initialized at (a,d,g) 0000 UTC on 5 July (b,e,h) 0000 UTC on 6 July and $(\mathbf{c}, \mathbf{f}, \mathbf{i}) 0000$ UTC on 18 July 2020 for different thresholds.

From the verification scores above, overall positive effects were found with the Himawari-8 radiance assimilation. To further investigate the impacts, Figure 12 presents the spatial distribution of 24-h accumulated precipitation from observations (OBS) and the two experiments (CTRL and HIM8), initialized at 0000 UTC on 5 July 6 July and 18 July. On 5 July, the observed rainfall (Figure 12a) was mainly distributed from west to east across Hubei Province, Anhui Province and Jiangsu Province. Heavy rainfall occurred in Hubei 
Province. The precipitation patterns in both CRTL (Figure 12d) and HIM8 (Figure 12g) are separated into two areas. Both experiments overestimated the precipitation in north Hunan and south Anhui but underestimated the precipitation in south Hubei. However, compared with CTRL, HIM8 simulated relatively weaker rainfall in south Anhui and Hubei, which reduced forecast errors against the observations. On 6 July the observed precipitation pattern (Figure 12b) moved to the east. The simulated rainfall area of CRTL (Figure 12e) slightly smaller than the observations, whereas HIM8 agreed more with the observations. Both experiments overestimated the intensity of heavy rainfall, especially for heavier rainfall $(>100 \mathrm{~mm})$. There was clear heavy rainfall in the northwest of Zhejiang Province according to CTRL, which was not found in observations. However, HIM8 corrected the overestimation in Zhejiang Province with radiance assimilation. On 18 July the area of precipitation became clearly larger than that on the first two days, covering most of the domain in the middle and north. Heavy rainfall occurred in Anhui Province. The CTRL and HIM8 experiments (Figure 12f,i) both clearly underestimated the heavy rainfall in Anhui Province. In Hunan Province, both experiments overestimated the precipitation compared with observations, and HIM8 showed relatively weaker rainfall intensity. Thus, the distribution of precipitation shows that simulated precipitation with radiance assimilation is more favorable with observations on the whole. However, it was also found that after assimilation, there was still some overestimation of precipitation, which should be further improved in the future.
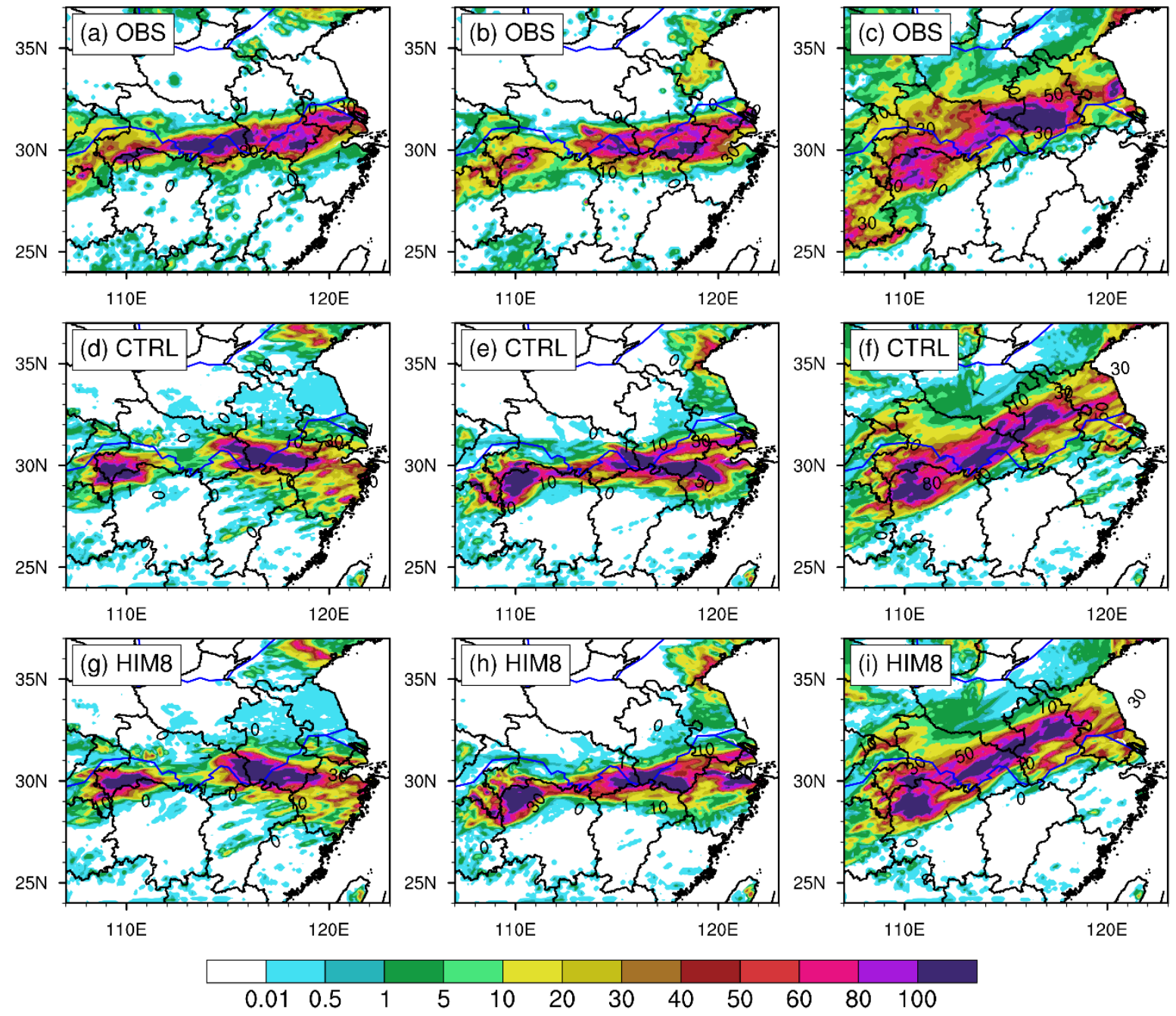

Figure 12. The distribution of 24-h accumulated precipitation initialized at (a,d,g) 0000 UTC on 5 July (b,e,h) 0000 UTC on 6 July and (c,f,i) 0000 UTC on 18 July 2020 from observations (first row) and CTRL (second row) and HIM8 (third row) experiments. 
Observations with higher temporal frequency are supposed to improve the prediction of rapidly changing systems, such as rapidly developing rainfall. Figure 13 shows the ETS for hourly accumulated precipitation with thresholds of $0.1,5$ and $10 \mathrm{~mm}$. The hourly ETS was calculated from 0000 to 2400 UTC on 5, 6 and 18 July. For 5 July the ETS results between the two experiments are quite close for the $0.1 \mathrm{~mm}$ threshold (Figure 13a), with a slightly higher ETS for HIM8 than for CTRL. For $5 \mathrm{~mm}$ (Figure 13d), higher ETS was found in HIM8 between 08Z and 14Z. For $10 \mathrm{~mm}$ (Figure 13g), the ETS clearly improved after $14 Z$ in HIM8 compared to CTRL, with the largest improvement at 20Z. As shown in Figure 9a, the precipitation strengthened between $14 Z$ and 20Z. The higher ETS at the $10 \mathrm{~mm}$ threshold indicates that HIM8 better predicted the rapid intensification of rainfall on 5 July. For $0.1 \mathrm{~mm}$ on 6 July (Figure 13b), the ETS values between the two experiments are close until 12Z, after which the ETS for HIM8 clearly increases hourly. For $5 \mathrm{~mm}$ (Figure 13e), HIM8 also clearly increases the ETS of CTRL, especially between 08Z and 17Z. For $10 \mathrm{~mm}$ (Figure 13h), the improvement becomes clear from 04Z. As shown in Figure 9b, there was a sharp decrease and increase in the precipitation amount before and after 16Z, showing that rainfall was developing rapidly. The larger hourly ETS of HIM8 during that time demonstrates the advantage of assimilating high temporal resolution observations in rapidly weakening precipitation forecasts. However, when the precipitation sharply strengthened, the performance of the two experiments was similar. For 18 July a higher ETS of HIM8 could be found at $0.1 \mathrm{~mm}$ (Figure 13c). HIM8 obtained a higher ETS from $08 \mathrm{Z}$ to $15 \mathrm{Z}$. For $5 \mathrm{~mm}$ (Figure 13f), the scores of the two experiments seemed to be close before 07Z, even with the lower ETS of HIM8. After 07Z, HIM8 showed an overall higher score until 18Z. For $10 \mathrm{~mm}$ (Figure 13i), the clearest improvement for HIM8 occurred between $08 \mathrm{Z}$ to $22 \mathrm{Z}$. Figure $9 \mathrm{c}$ shows that the rainfall on 18 July was continuously strengthening, with the strongest intensification around 18Z. A higher ETS of HIM8 was found at that time in different thresholds. These results show that the radiance assimilation experiment better predicted the hourly accumulated precipitation.

The average percentages of relative improvement are also displayed in Table 4 . For different days, the hourly ETS on 5 July improved with assimilation by about 7.19\%, with a maximum improvement of $15.52 \%$ in the $10 \mathrm{~mm}$ threshold. The ETS on 6 July improved by $8.53 \%$ on average, with the largest improvement of $11.20 \%$ in $10 \mathrm{~mm}$. The relative improvement on 18 July was $7.83 \%$. Comparing the different thresholds, the largest improvement was found in $10 \mathrm{~mm}$. This shows that the prediction for heavy rainfall in a short time with assimilation is better than that without assimilation. From all the cases, the ETS of HIM8 increased by $7.85 \%$ compared to CTRL on average. Overall, the assimilation of Himawari-8 radiance with the POD-4DEnVar method has positive impacts on short-term precipitation forecast, especially for rapidly developing precipitation.

Table 4. The relative improvement in hourly ETS in HIM8 compared with CTRL.

\begin{tabular}{ccccc}
\hline & 5 July & 6 July & 18 July & Average \\
\hline $0.1 \mathrm{~mm}$ & $2.09 \%$ & $5.40 \%$ & $4.20 \%$ & $3.90 \%$ \\
$5 \mathrm{~mm}$ & $3.96 \%$ & $9.0 \%$ & $7.90 \%$ & $6.95 \%$ \\
$10 \mathrm{~mm}$ & $15.52 \%$ & $11.20 \%$ & $11.40 \%$ & $12.71 \%$ \\
Average & $7.19 \%$ & $8.53 \%$ & $7.83 \%$ & $7.85 \%$ \\
\hline
\end{tabular}




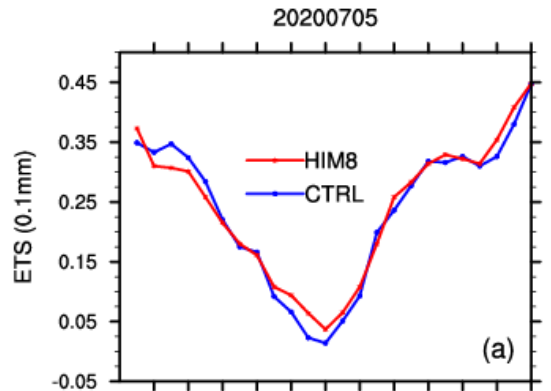

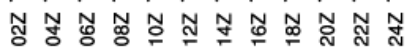
Time

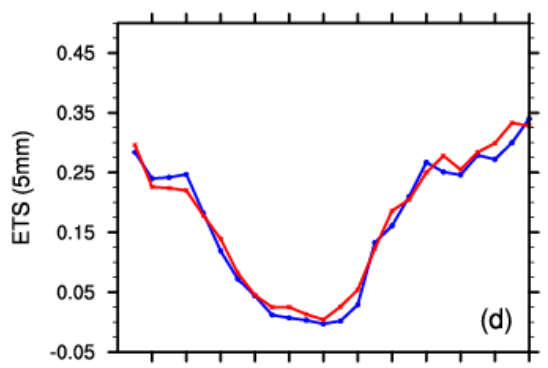

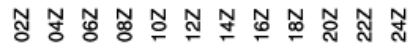
Time 20200705

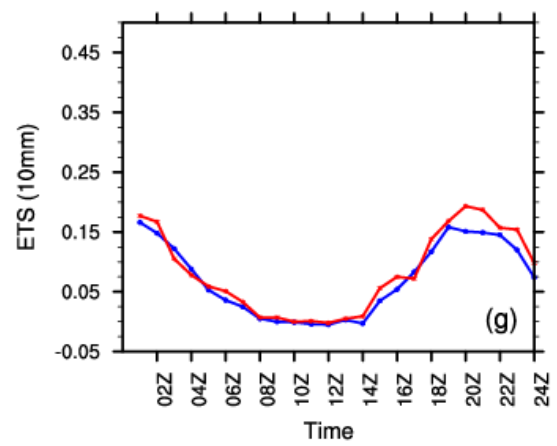

20200706

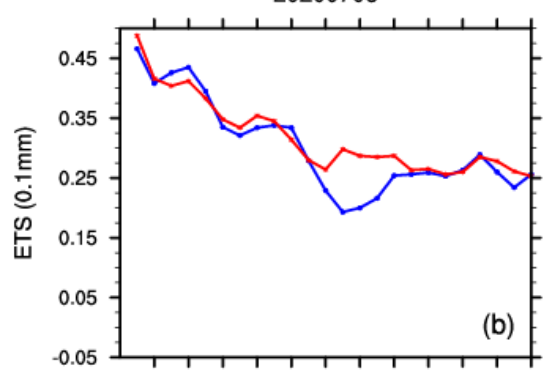

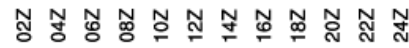
Time 20200706

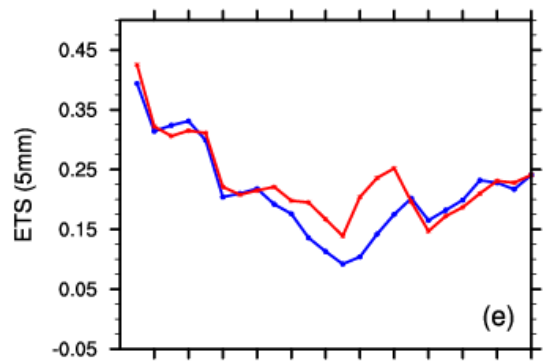

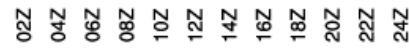
Time 20200706

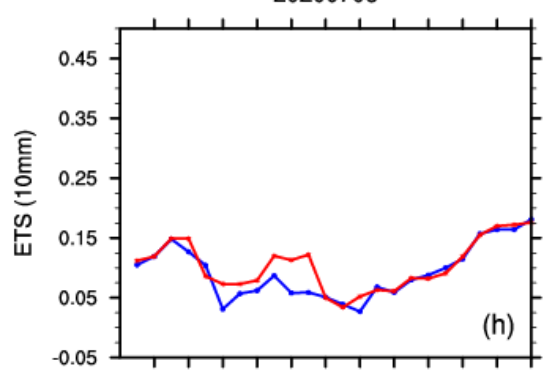

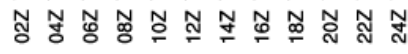

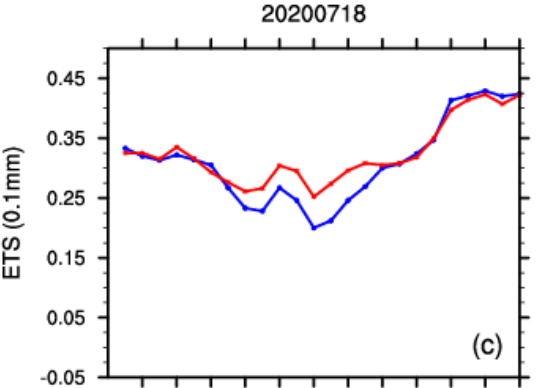

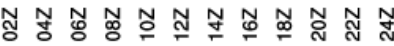
Time 20200718

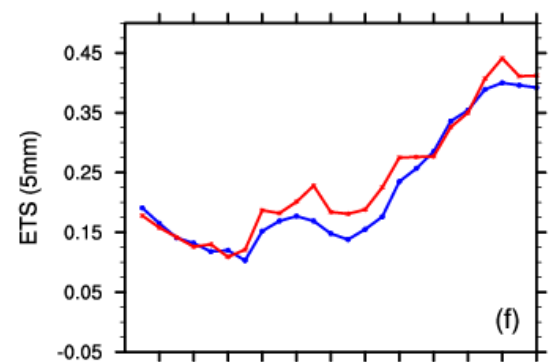

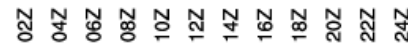
Time 20200718

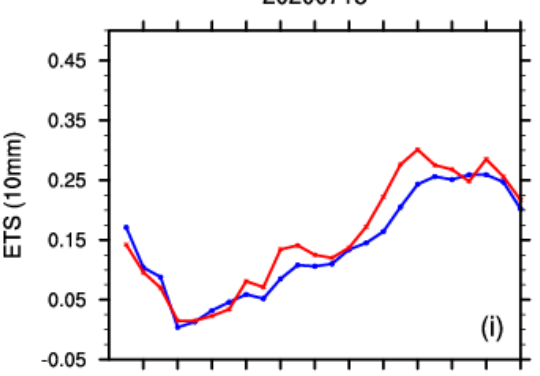

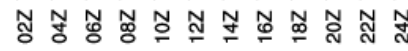

Figure 13. The ETS evolution of hourly precipitation on (a,d,g) 5 July (b,e,h) 6 July and (c,f,i) 18 July 2020 for different thresholds.

\subsection{Discussion}

\subsubsection{The Initial Increments}

As shown in the evaluation results above, assimilating Himawari-8 radiance reduces the average bias and RMSE of meteorological elements' analyses and forecasts. In addition, assimilation further improves the score skills of quantitative rainfall forecast as well as the structure, amplitude and location forecast. To further investigate the impacts of radiance assimilation, the initial increments are analyzed and discussed in this section. Initial increments show the difference between analysis and background, representing the change from background to analysis by assimilating Himawari-8 radiance.

On 18 July, heavy rainfall appeared in the middle of Anhui Province $\left(31^{\circ} \mathrm{N}-33^{\circ} \mathrm{N}\right.$, $\left.114^{\circ} \mathrm{E}-118^{\circ} \mathrm{E}\right)$. Figure 14 shows the spatial distribution of the water vapor mixing ratio (QVAPOR), temperature (T) and vertical velocity $(\mathrm{W})$ at different pressure levels at 0000 UTC on 18 July 2020, when rainfall of varying intensity occurred around $30^{\circ} \mathrm{N}$ (Figure 12). The vectors represent the analysis of horizontal wind field, which provides the circulation patterns. For QVAPOR, the spatial distribution of increments is all over the inner domain, mostly in the precipitation area. The water vapor at $700 \mathrm{hPa}$ was increased in the middle of Anhui after assimilation, with a maximum of almost $0.8 \mathrm{~g} / \mathrm{kg}$. At $500 \mathrm{hPa}$, the increments varied in different areas, with both increases and decreases in water vapor in Anhui. Thus, assimilation of Himawari- 8 radiance mainly increases the lower-level 
water vapor in the heavy rainfall area. More water vapor transport in the lower level is provided for the development of precipitation, helping to strengthen the heavy rainfall in the middle of Anhui Province. The change in temperature after assimilation was slight in the precipitation area, which was dispersed and small, with few cooling effects at $500 \mathrm{hPa}$ and few warming effects at $700 \mathrm{hPa}$. Thus, assimilating Himawari-8 radiance has little effect on temperature in the precipitation area. However, vertical velocity increments were clearly found in the precipitation area at both 500 and $700 \mathrm{hPa}$. The positive increments were found in the area where there was clear horizontal wind convergence at $700 \mathrm{hPa}$. Horizontal wind convergence at the lower level means that there is clear air updraft. Thus, the positive increments indicate that assimilation further strengthens the updraft in the precipitation area, which is beneficial for precipitation development. In addition, the increment at $500 \mathrm{hPa}$ is stronger than that at $700 \mathrm{hPa}$, demonstrating that Himawari-8 radiance changes the mid-level vertical velocity more than the lower-level one. Overall, the impacts of Himawari-8 radiance on the initial field are mainly found in water vapor and vertical velocity in precipitation areas, which helps improve rainfall prediction.
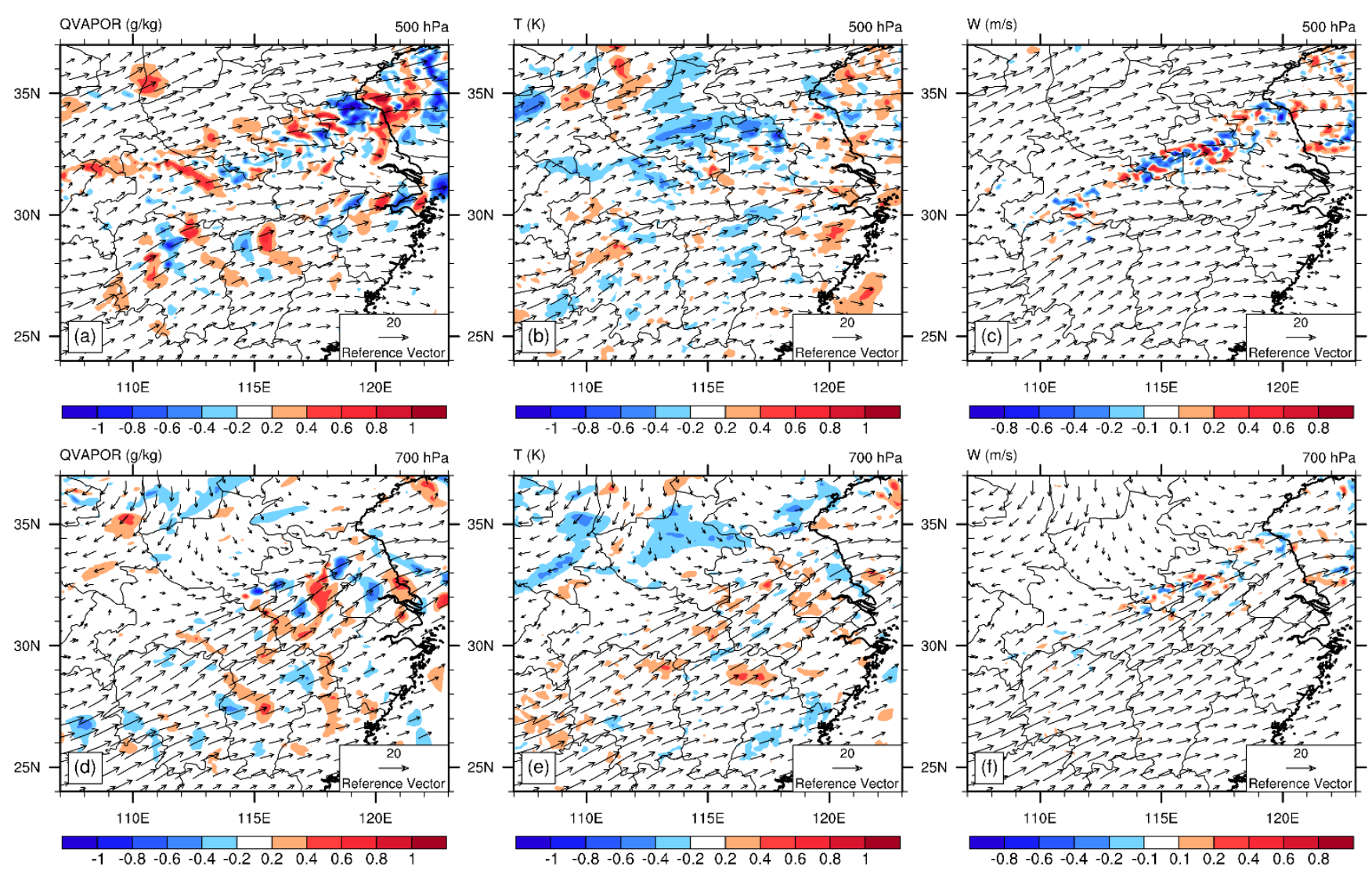

Figure 14. The increments in (a,d) water vapor mixing ratio (shaded; $g / k g),(\mathbf{b}, \mathbf{e})$ temperature (shaded; $K)$ and $(\mathbf{c}, \mathbf{f})$ vertical velocity (shaded; m/s) at 0000 UTC on 18 July 2020. (a-c) $500 \mathrm{hPa}$ and (d-f) $700 \mathrm{hPa}$. The vectors show the direction and magnitude of the horizontal wind field from analysis.

\subsubsection{The Effect of Observation Frequency}

The hourly precipitation ETS results show that assimilation of every 10-min radiance data with POD-4DEnVar improves the prediction of rapidly changed rainfall events. To investigate the advantages of assimilating high observing frequency radiance data, another assimilation experiment was conducted, HIM8-1h, which assimilates all the observations in CTRL plus every 1-h Himawari-8 radiance. Correspondingly, the assimilation window was set to $6 \mathrm{~h}$, with seven observations made within the assimilation window. An ensemble was made for HIM8-1h with the same method described in Section 2.2, but with a different 
temporal resolution. The other configurations in assimilation and forecast procedure are the same as HIM8.

Figure 15 shows the ETS results in HIM8 and HIM8-1h on 18 July 2020 as a case study. For 24-h accumulated precipitation (Figure 15a), in general, the ETS for HIM8 was increased compared to HIM8-1h. The increase was much more apparent in the $0.1,10$ and $20 \mathrm{~mm}$ thresholds. On average, HIM8 improved the 24-h accumulated precipitation ETS by $12.75 \%$ compared to HIM8-1h, with the greatest improvement of $28.66 \%$ in $100 \mathrm{~mm}$ precipitation. As the results in Section 4.2 demonstrate the positive impacts of assimilation on the rapidly developed rainfall, the same evaluation was carried out on the hourly evolution of precipitation. Figure 15b-d display the hourly accumulated precipitation ETS for different thresholds on 18 July. For $0.1 \mathrm{~mm}$ (Figure 15b), the ETS of HIM8 improved between $05 \mathrm{Z}$ and 21Z. Clear improvements were found when the precipitation was continuously strengthening. The same results appeared at larger thresholds, where, in the first few hours, HIM8-1h presented better ETS results than HIM8. However, as the precipitation developed, assimilating every-10-min radiance yielded clearly higher ETS results than HIM8-1h. Averaging the different thresholds, the hourly accumulated precipitation ETS improved by $15.88 \%$ in HIM8 compared to HIM8-1h. The largest increases in ETS were found at $15 \mathrm{Z}$ for $0.1 \mathrm{~mm}, 12 \mathrm{Z}$ for $5 \mathrm{~mm}$ and $12 \mathrm{Z}$ for $10 \mathrm{~mm}$ thresholds. As shown in Figure 9, the precipitation on 18 July continuously strengthened at $08 \mathrm{Z}$ and $18 \mathrm{Z}$. Thus, the advantage of assimilating high observational frequency data is revealed when the precipitation is rapidly strengthening.
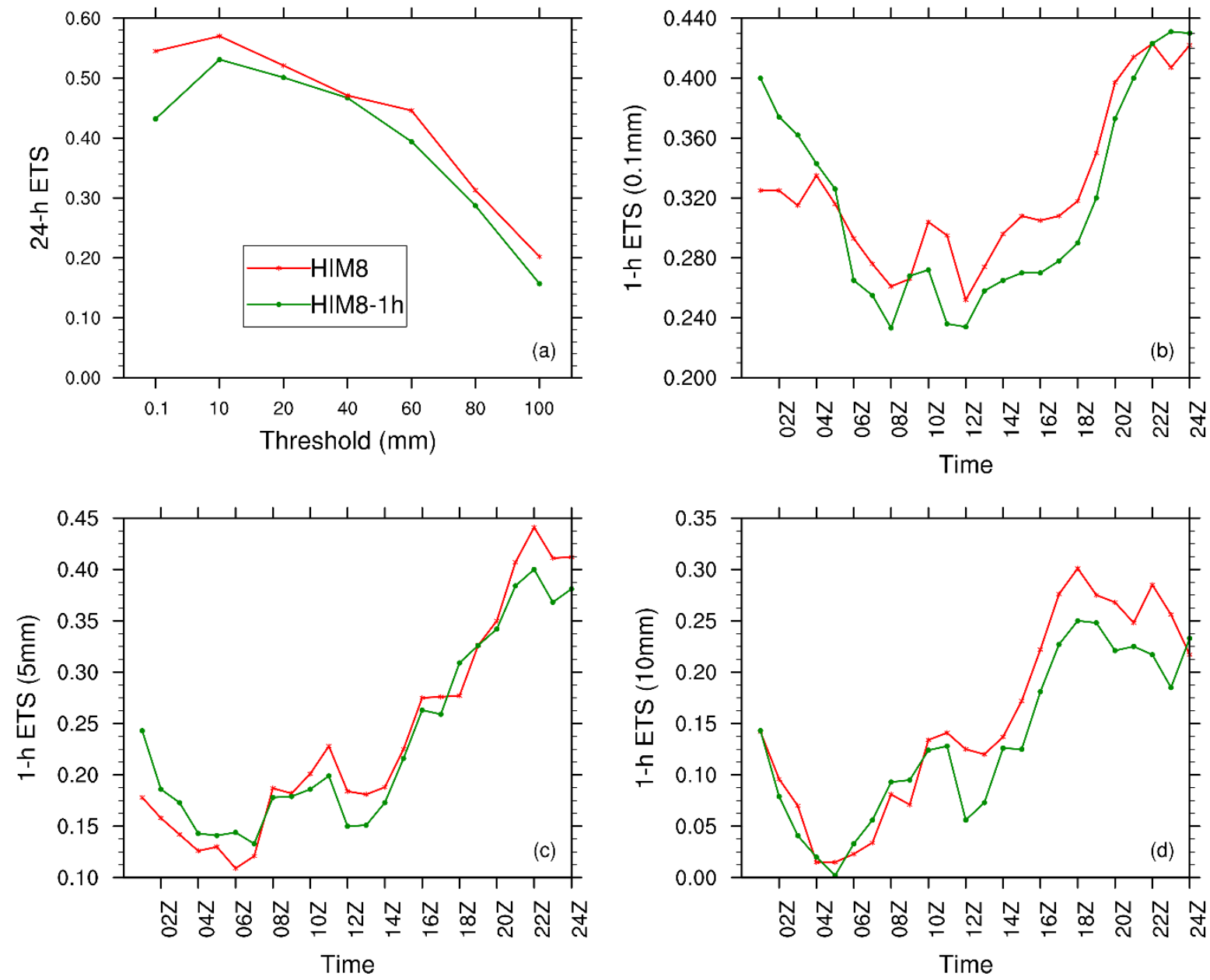

Figure 15. (a) The 24-h accumulated precipitation ETS on 18 July for different thresholds. (b-d) The hourly accumulated precipitation ETS for $0.1,5$ and $10 \mathrm{~mm}$ on 18 July. The green lines represent the HIM8-1h experiment and red represents HIM8. 


\subsubsection{The Effect of the Assimilation Method}

To quantitatively discuss the advantage of assimilating Himawari- 8 radiance data with the POD-4DEnVar method, it was compared with the traditional 3DVar assimilation method [59]. The analysis time of 3DVar was set to 0000 UTC on 18 July with the background field provided by a 6-h forecast using the WRF model. The assimilation window was $\pm 3 \mathrm{~h}$, with the analysis time at the center of the window. The other configurations were the same as in the POD-4DEnVar experiments. A comparison of precipitation forecasts was completed. Tables 5 and 6 display the ETS values of 24-h and hourly accumulated precipitation with different assimilation methods. On average, assimilation with the POD-4DEnVar method improved the $24-\mathrm{h}$ accumulated precipitation by $11.88 \%$ (Table 5 ) compared to assimilation with the 3Dvar method. The hourly accumulated precipitation ETS was also evaluated between the two assimilation methods. The results show that the POD-4DEnVar method improved the hourly ETS by $11 \%$ on average (Table 6). Overall, the quantitative results indicate that assimilating Himawari-8 radiance data with the POD-4DEnVar method outperforms the traditional 3DVar method.

Table 5. The ETS values of 24-h accumulated precipitation for different thresholds.

\begin{tabular}{cccccccc}
\hline & $\mathbf{0 . 1} \mathbf{~} \mathbf{m m}$ & $\mathbf{1 0} \mathbf{~} \mathbf{m}$ & $\mathbf{2 0} \mathbf{~} \mathbf{m}$ & $\mathbf{4 0} \mathbf{~} \mathbf{m}$ & $\mathbf{6 0} \mathbf{~} \mathbf{m}$ & $\mathbf{8 0} \mathbf{~} \mathbf{m}$ & $\mathbf{1 0 0} \mathbf{~} \mathbf{m}$ \\
\hline POD-4DEnVar & 0.545 & 0.57 & 0.521 & 0.471 & 0.446 & 0.313 & 0.202 \\
3DVar & 0.487 & 0.453 & 0.471 & 0.442 & 0.385 & 0.289 & 0.194 \\
\hline
\end{tabular}

Table 6. The ETS values of hourly accumulated precipitation for different thresholds.

\begin{tabular}{lcccccc}
\hline & \multicolumn{2}{c}{$\mathbf{0 . 1} \mathbf{~ m m}$} & \multicolumn{2}{c}{$\mathbf{5} \mathbf{~ m m}$} & \multicolumn{2}{c}{$\mathbf{1 0} \mathbf{~ m m}$} \\
\cline { 2 - 6 } & POD-4DEnVar & 3DVar & POD-4DEnVar & 3DVar & POD-4DEnVar & 3DVar \\
\hline $01 Z$ & 0.325 & 0.294 & 0.178 & 0.177 & 0.142 & 0.148 \\
$02 Z$ & 0.325 & 0.323 & 0.158 & 0.19 & 0.096 & 0.103 \\
$03 Z$ & 0.315 & 0.334 & 0.142 & 0.18 & 0.07 & 0.103 \\
$04 Z$ & 0.335 & 0.353 & 0.126 & 0.179 & 0.015 & 0.092 \\
$05 Z$ & 0.316 & 0.331 & 0.13 & 0.165 & 0.015 & 0.067 \\
$06 Z$ & 0.293 & 0.286 & 0.109 & 0.136 & 0.023 & 0.052 \\
$07 Z$ & 0.276 & 0.256 & 0.121 & 0.125 & 0.034 & 0.072 \\
$08 Z$ & 0.261 & 0.234 & 0.187 & 0.143 & 0.081 & 0.042 \\
$09 Z$ & 0.266 & 0.213 & 0.182 & 0.161 & 0.071 & 0.064 \\
$10 Z$ & 0.304 & 0.233 & 0.201 & 0.167 & 0.134 & 0.08 \\
$11 Z$ & 0.295 & 0.224 & 0.228 & 0.159 & 0.141 & 0.096 \\
$12 Z$ & 0.252 & 0.202 & 0.184 & 0.117 & 0.125 & 0.072 \\
$13 Z$ & 0.274 & 0.218 & 0.181 & 0.133 & 0.12 & 0.08 \\
$14 Z$ & 0.296 & 0.245 & 0.188 & 0.175 & 0.137 & 0.118 \\
$15 Z$ & 0.308 & 0.277 & 0.225 & 0.224 & 0.172 & 0.123 \\
$16 Z$ & 0.305 & 0.284 & 0.275 & 0.262 & 0.222 & 0.165 \\
$17 Z$ & 0.308 & 0.285 & 0.276 & 0.266 & 0.276 & 0.209 \\
$18 Z$ & 0.318 & 0.277 & 0.277 & 0.258 & 0.301 & 0.216 \\
$19 Z$ & 0.35 & 0.301 & 0.326 & 0.282 & 0.275 & 0.235 \\
$20 Z$ & 0.397 & 0.333 & 0.35 & 0.304 & 0.268 & 0.216 \\
$21 Z$ & 0.414 & 0.345 & 0.407 & 0.319 & 0.248 & 0.205 \\
$22 Z$ & 0.423 & 0.386 & 0.441 & 0.352 & 0.285 & 0.255 \\
$23 Z$ & 0.407 & 0.396 & 0.411 & 0.364 & 0.256 & 0.226 \\
$24 Z$ & 0.422 & 0.409 & 0.412 & 0.41 & 0.217 & 0.188 \\
\hline & & & & & & \\
\hline
\end{tabular}

\section{Conclusions}

In this study, the potential impacts of assimilating every-10-min Himawari- 8 radiance data were investigated based on a four-dimensional ensemble variation assimilation method. To assimilate Himawari-8 AHI radiance data, quality control, especially cloud detection, was first conducted. Based on the POD-4DEnVar method, the assimilation window was designed according to the frequency of Himawari-8 observations used in this study. 
In addition, historical forecasts and physical ensembles were combined in order to make ensembles as well as reduce computational costs. The results suggest that the simulated radiance after quality control and bias correction procedures agrees more with observations, indicating that radiance with "good" quality is guaranteed in the assimilation system.

The impacts of Himawari- 8 radiance assimilation on the analysis and forecast of the main meteorological elements were examined. Clear positive effects were found for geopotential, wind field and relative humidity. The impacts on temperature and water vapor mixing ratio were small but still positive overall. An evaluation of rainfall prediction was also conducted to further examine the impacts of assimilation. On average, the HIM8 experiment improved the ETS of 24-h accumulated precipitation for all the rainfall cases compared to the CTRL experiment. The SAL results also indicate that assimilation can improve the precipitation prediction from the perspective of structure, amplitude and location. The increments indicate that assimilation strengthens the water vapor at a lower level and vertical velocity in middle and lower levels, especially in the rainfall area, which helps fix the underestimated heavy rainfall prediction. Moreover, an additional experiment assimilating Himawari-8 radiance every $1 \mathrm{~h}$ was conducted. In comparison, the 24-h ETS clearly improved when assimilating every-10-min Himawari-8 radiance. The hourly ETS evolution suggests that assimilation of high observing frequency data can improve the prediction of rapidly intensified precipitation. Thus, the observations with high observing frequency can be utilized more appropriately with POD-4DEnVar. Assimilation of Himawari-8 radiance data was also compared with the traditional 3DVar method. The quantitative ETS results show that POD-4DEnVar outperforms the 3DVar method in general.

This study encourages the assimilation of every-10-min radiance data from the Himawari-8 geostationary satellite with the POD-4DEnVar method. The results in this study demonstrate that the assimilation has the potential to improve numerical weather predictions. However, further studies still need to be conducted in the future. On the one hand, higher quality ensembles need to be produced while not increasing the computational cost too much. On the other hand, this study only assimilated clear-sky radiance from the Himawari-8 satellite. However, most severe weather is associated with dense clouds and precipitation. Assimilating observations affected by clouds and precipitation may provide more information. Several studies have investigated the assimilation of all-sky Himawari-8 radiance with traditional methods $[47,48]$. Thus, assimilation of all-sky Himawari-8 radiance data with the POD-4DEnVar method may be the next step of our future work in order to further improve severe weather forecasts.

Author Contributions: Conceptualization, L.Z. and J.W.; methodology, L.Z. and J.W.; writingoriginal draft preparation, J.W.; writing-review and editing, J.G., X.W. and M.Z.; funding acquisition, L.Z. and Y.W. All authors have read and agreed to the published version of the manuscript.

Funding: This research was funded by the National Natural Science Foundation of China under Grant 41975066 and Grant 42005053, and by the Research Project of National University of Defense Technology under Grant ZK21-46.

Institutional Review Board Statement: Not applicable.

Informed Consent Statement: Not applicable.

Conflicts of Interest: The authors declare no conflict of interest.

\section{References}

1. Evensen, G. Sequential data assimilation with a nonlinear quasi-geostrophic. J. Geophys. Res. 1994, 99, 20.

2. Evensen, G. The ensemble Kalman filter: Theoretical formulation and practical implementation. Ocean Dyn. 2003, 53, 343-367. [CrossRef]

3. Hamill, T.M. Ensemble-based atmospheric data assimilation. In Predictability of Weather and Climate; Palmer, T., Hagedorn, R., Eds.; Cambridge University Press: Cambridge, UK, 2006; pp. 124-156.

4. Derber, J.C.; Wu, W.-S. The Use of TOVS Cloud-Cleared Radiances in the NCEP SSI Analysis System. Mon. Weather Rev. 1998, 126, 2287-2290. [CrossRef] 
5. Chen, D.; Xue, J. An Overview on Recent Progresses of the Operational Numerical Weather Prediction Models. Acta Meteorol. Sin. 2004, 62, 623-633.

6. Barker, D.M.; Huang, W.; Guo, Y.-R.; Bourgeois, A.J.; Xiao, Q.N. A Three-Dimensional Variational Data Assimilation System for MM5_Implementation and Initial Results. Mon. Weather Rev. 2004, 132, 897-914. [CrossRef]

7. Bouttier, G.K.F. Observing-system experiments in the ECMWF 4D-Var data assimilation system. Q. J. R. Meteorol. Soc. 2001, 127, 1469-1488. [CrossRef]

8. Huang, X.Y.; Xiao, Q.; Barker, D.M.; Zhang, X.; Michalakes, J.; Huang, W.; Henderson, T.; Bray, J.; Chen, Y.; Ma, Z.; et al. Four-Dimensional Variational Data Assimilation for WRF: Formulation and Preliminary Results. Mon. Weather Rev. 2009, 137, 299-314. [CrossRef]

9. Zhang, X.; Huang, X.Y.; Liu, J.; Poterjoy, J.; Weng, Y.; Zhang, F.; Wang, H. Development of an Efficient Regional Four-Dimensional Variational Data Assimilation System for WRF. J. Atmos. Ocean Technol. 2014, 31, 2777-2794. [CrossRef]

10. Pellerin, S.; Laroche, S.; Tanguay, M.; Gauthier, P.; Morneau, J. Extension of 3DVAR to 4DVAR: Implementation of 4DVAR at the Meteorological Service of Canada. Mon. Weather Rev. 2007, 135, 2339-2354.

11. Houtekamer, P.L.; Mitchell, H.L. Data Assimilation Using an Ensemble Kalman Filter Technique. Mon. Weather Rev. 1998, 126, 796. [CrossRef]

12. Wang, X.; Barker, D.M.; Snyder, C.; Hamill, T.M. A Hybrid ETKF-3DVAR Data Assimilation Scheme for the WRF Model. Part I: Observing System Simulation Experiment. Mon. Weather Rev. 2008, 136, 5116-5131. [CrossRef]

13. Wang, X.; Barker, D.M.; Snyder, C.; Hamill, T.M. A Hybrid ETKF-3DVAR Data Assimilation Scheme for the WRF Model. Part II: Real Observation Experiments. Mon. Weather Rev. 2008, 136, 5132-5147. [CrossRef]

14. Lorenc, A.C. The potential of the ensemble Kalman filter for NWP-A comparison with 4D-Var. Q. J. R. Meteorol. Soc. 2003, 129, 3183-3203. [CrossRef]

15. Geer, A.J.; Lonitz, K.; Weston, P.; Kazumori, M.; Okamoto, K.; Zhu, Y.; Liu, E.H.; Collard, A.; Bell, W.; Migliorini, S.; et al. All-sky satellite data assimilation at operational weather 2018. Q. J. R. Meteorol. Soc. 2018, 114, 1191-1217. [CrossRef]

16. Xiong, C.; Zhang, L.; Guan, J.; Tao, H.; Su, J. Development and application of ensemble-variational data assimilation methods. Adv. Earth Sci. 2013, 28, 648-656.

17. Hamill, T.M.; Snyder, C. A Hybrid Ensemble Kalman Filter-3D Variational Analysis Scheme. Mon. Weather Rev. 2000, 128, 2905-2919. [CrossRef]

18. Wang, X. Application of the WRF Hybrid ETKF-3DVAR data assimilation system for hurricane track forecasts. Weather Forecast 2011, 26, 868-884. [CrossRef]

19. Poterjoy, J.; Zhang, M.; Zhang, F. E3DVar: Coupling an Ensemble Kalman Filter with Three-Dimensional Variational Data Assimilation in a Limited-Area Weather Prediction Model and Comparison to E4DVar. Mon. Weather Rev. 2013, 141, 900-917.

20. Zhang, M.; Zhang, F. E4DVar: Coupling an Ensemble Kalman Filter with Four-Dimensional Variational Data Assimilation in a Limited-Area Weather Prediction Model. Mon. Weather Rev. 2012, 140, 587-600. [CrossRef]

21. Buehner, M.; McTaggart-Cowan, R.; Beaulne, A.; Charette, C.; Garand, L.; Heilliette, S.; Lapalme, E.; Laroche, S.; Macpherson, S.R.; Morneau, J.; et al. Implementation of Deterministic Weather Forecasting Systems Based on Ensemble-Variational Data Assimilation at Environment Canada. Part I: The Global System. Mon. Weather Rev. 2015, 143, 2532-2559. [CrossRef]

22. Qiu, C.; Shao, A.; Xu, Q.; Wei, L. Fitting model fields to observations by using singular value decomposition: An ensemble-based 4DVar approach. J. Geophys. Res. 2007, 112, D11105. [CrossRef]

23. Wang, B.; Liu, J.; Wang, S.; Cheng, W.; Juan, L.; Liu, C.; Xiao, Q.; Kuo, Y.H. An economical approach to four-dimensional variational data assimilation. Adv. Atmos. Sci. 2010, 27, 715-727. [CrossRef]

24. Tian, X.; Xie, Z.; Dai, A. An ensemble-based explicit four-dimensional variational assimilation method. J. Geophys. Res. 2008, 113. [CrossRef]

25. Tian, X.; Xie, Z. An explicit four-dimensional variational data assimilation method based on the proper orthogonal decomposition: Theoretics and evaluation. Sci. China Ser. D 2009, 52, 279-286. [CrossRef]

26. Tian, X.; Xie, Z.; Sun, Q. A POD-based ensemble four-dimensional variational assimilation method. Tellus 2011, 63, 805-816. [CrossRef]

27. Tian, X.; Xie, Z.; Liu, Y.; Cai, Z.; Fu, Y.; Zhang, H.; Feng, L. A joint data assimilation system (Tan-Tracker) to simultaneously estimate surface $\mathrm{CO}_{2}$ fluxes and 3-D atmospheric $\mathrm{CO}_{2}$ concentrations from observations. Atmos. Chem. Phys. 2014, 14, 1328113293. [CrossRef]

28. Collard, A.; Hilton, F.; Forsythe, M.; Candy, B. From Observations to Forecasts-Part 8: The use of satellite observations in numerical weather prediction. Q. J. R. Meteorol. Soc. 2011, 66, 31-36. [CrossRef]

29. Köpken, C.; Kelly, G.; Thépaut, J.-N. Assimilation of Meteosat radiance data within the 4D-Var system at ECMWF: Assimilation experiments and forecast impact. Q. J. R. Meteorol. Soc. 2004, 130, 2277-2292. [CrossRef]

30. Ha, S.-Y.; Snyder, C.; Schwartz, C.S.; Liu, Z. Impact of Assimilating AMSU-A Radiances on Forecasts of 2008 Atlantic Tropical Cyclones Initialized with a Limited-Area Ensemble Kalman Filter. Mon. Weather Rev. 2012, 140, 4017-4034.

31. Zou, X.; Weng, F.; Zhang, B.; Lin, L.; Qin, Z.; Tallapragada, V. Impacts of assimilation of ATMS data in HWRF on track and intensity forecasts of 2012 four landfall hurricanes. J. Geophys. Res. 2013, 118, 11-558. [CrossRef]

32. Shen, F.; Min, J. Assimilating AMSU-a radiance data with the WRF hybrid En3DVAR system for track predictions of Typhoon Megi (2010). Adv. Atmos. Sci. 2015, 32, 1231-1243. [CrossRef] 
33. Lu, Q.; Bell, W.; Bauer, P.; Bormann, N.; Peubey, C. An evaluation of FY-3A satellite data for numerical weather prediction. Q. J. R. Meteorol. Soc. 2011, 137, 1298-1311. [CrossRef]

34. Chen, K.; English, S.; Bormann, N.; Zhu, J. Assessment of FY-3A and FY-3B MWHS observations. Weather Forecast. 2015, 30, 1280-1290. [CrossRef]

35. Li, J.; Liu, G. Direct assimilation of Chinese FY-3C Microwave Temperature Sounder-2radiances in the global GRAPES system. Atmos. Meas. Tech. 2016, 9, 3095-3113. [CrossRef]

36. Lawrence, H.; Bormann, N.; Geer, A.J.; Lu, Q.; English, S.J. Evaluation and Assimilation of the Microwave Sounder MWHS-2 Onboard FY-3C in the ECMWF Numerical Weather Prediction System. IEEE Trans. Geosci. Remote Sens. 2018, 56, 3333-3349. [CrossRef]

37. Zou, X.; Qin, Z.; Weng, F. Improved Coastal Precipitation Forecasts with Direct Assimilation of GOES-11/12 Imager Radiances. Mon. Weather Rev. 2011, 139, 3711-3729. [CrossRef]

38. Zhang, F.; Minamide, M.; Clothiaux, E.E. Potential impacts of assimilating all-sky infrared satellite radiances from GOES-R on convection-permitting analysis and prediction of tropical cyclones. Geophys. Res. Lett. 2016, 43, 2954-2963. [CrossRef]

39. Qin, Z.; Zou, X. Direct Assimilation of ABI Infrared Radiances in NWP Models. IEEE J. Sel. Top. Appl. Earth Obs. Remote Sens. 2018, 11, 2022-2033. [CrossRef]

40. Szyndel, M.D.E.; Kelly, G.; Thépaut, J.N. Evaluation of potential benefit of assimilation of SEVIRI water vapour radiance data from Meteosat-8 into global numerical weather prediction analyses. Atmos. Sci. Lett. 2005, 6, 105-111. [CrossRef]

41. Stengel, M.; Undén, P.; Lindskog, M.; Dahlgren, P.; Gustafsson, N.; Bennartz, R. Assimilation of SEVIRI infrared radiances with HIRLAM 4D-Var. Q. J. R. Meteorol. Soc. 2009, 135, 2100-2109. [CrossRef]

42. Wang, Y.; He, J.; Chen, Y.; Min, J. The Potential Impact of Assimilating Synthetic Microwave Radiances Onboard a Future Geostationary Satellite on the Prediction of Typhoon Lekima Using the WRF Model. Remote Sens. 2021, 13, 886. [CrossRef]

43. Bessho, K.; Date, K.; Hayashi, M.; Ikeda, A.; Imai, T.; Inoue, H.; Kumagai, Y.; Miyakawa, T.; Murata, H.; Ohno, T.; et al. An Introduction to Himawari-8/9-Japan's New-Generation Geostationary Meteorological Satellites. J. Meteorol. Soc. Jpn. Ser. II 2016, 94, 151-183. [CrossRef]

44. Ma, Z.; Maddy, E.S.; Zhang, B.; Zhu, T.; Boukabara, S.A. Impact Assessment of Himawari-8 AHI Data Assimilation in NCEP GDAS/GFS with GSI. J. Atmos. Ocean Technol. 2017, 34, 797-815. [CrossRef]

45. Kazumori, M. Assimilation of Himawari-8 Clear Sky Radiance Data in JMA's Global and Mesoscale NWP Systems. J. Meteorol. Soc. Jpn. Ser. II 2018, 96, 173-192. [CrossRef]

46. Wang, Y.; Liu, Z.; Yang, S.; Min, J.; Chen, L.; Chen, Y.; Zhang, T. Added Value of Assimilating Himawari-8 AHI Water Vapor Radiances on Analyses and Forecasts for "7.19" Severe Storm Over North China. J. Geophys. Res. 2018, 123, 3374-3394. [CrossRef]

47. Sawada, Y.; Okamoto, K.; Kunii, M.; Miyoshi, T. Assimilating every-10-minute Himawari-8 infrared radiances to improve convective predictability. J. Geophys. Res. Atmos. 2019, 124, 2546-2561. [CrossRef]

48. Honda, T.; Miyoshi, T.; Lien, G.; Nishizawa, S.; Yoshida, R.; Adachi, S.A.; Terasaki, K.; Okamoto, K.; Tomita, H.; Bessho, K. Assimilating All-Sky Himawari-8 Satellite Infrared Radiances: A Case of Typhoon Soudelor (2015). Mon. Weather Rev. 2018, 146, 213-229. [CrossRef]

49. Zhang, M.; Zhang, L.; Zhang, B. FY-3A Microwave Data Assimilation Based on the POD-4DEnVar Method. Atmosphere 2018, 9 , 189. [CrossRef]

50. Zhang, M.; Zhang, L.; Zhang, B.; Guan, J.; You, W. Assimilation of MWHS and MWTS radiance data from the FY-3A satellite with the POD-3DEnVar method for forecasting heavy rainfall. Atmos. Res. 2019, 219, 95-105. [CrossRef]

51. Xu, Q.; Wei, L.; Lu, H.; Qiu, C.; Zhao, Q. Time-expanded sampling for ensemble-based filters: Assimilation experiments with a shallow-water equation model. J. Geophys. Res. 2008, 113. [CrossRef]

52. Radhakrishnan, C.; Balaji, C. Impact of physics parameterization and 3DVAR data assimilation on prediction of tropical cyclones in the Bay of Bengal region. Nat. Hazards 2016, 80, 223-247.

53. Aksoy, A.; Meng, Z.; Zhang, F. Tests of an Ensemble Kalman Filter for Mesoscale and Regional-Scale Data Assimilation. Part I: Perfect Model Experiments. Mon. Weather Rev. 2006, 134, 722-736.

54. Lan, W.; Zhu, J.; Xue, M.; Lei, T.; Gao, J. Storm-scale ensemble Kalman filter data assimilation experiments using simulated Doppler radar data. Part II: Imperfect model tests. Chin. J. Atmos. Sci. 2010, 34, 737-753. (In Chinese)

55. Yang, Y.; Zhang, L.; Zhang, B.; You, W.; Zhang, M.; Xie, B. Application of a Physical Ensemble Method in the POD-4DEnVar. Weather Forecast. 2018, 33, 1567-1585. [CrossRef]

56. Ishida, H.; Nakajima, T.Y. Development of an unbiased cloud detection algorithm for a spaceborne multispectral imager. J. Geophys. Res. 2009, 114, D07206. [CrossRef]

57. Auligné, T.; McNally, A.P.; Dee, D.P. Adaptive bias correction for satellite data in a numerical weather prediction system. Q. J. R. Meteorol. Soc. 2007, 133, 631-642. [CrossRef]

58. Skamarock, W.C.; Klemp, J.B.; Dudhia, J.; Gill, D.O.; Barker, D.; Duda, M.G.; Powers, J.G. A Description of the Advanced Research WRF Version 3. NCAR Tech. No. 2008, 113. [CrossRef]

59. Yesubabu, V.; Islam, S.; Sikka, D.R.; Kaginalkar, A.; Kashid, S.; Srivastava, A.K. Impact of variational assimilation technique on simulation of a heavy rainfall event over Pune, India. Nat. Hazards 2014, 71, 639-658. [CrossRef]

60. Han, Y.; van Delst, P.; Liu, Q.; Weng, F.; Yan, B.; Han, Y. JCSDA Community radiative Transfer Model (CRTM)-Version 1. NOAA Tech. Rep. NESDIS 2006, 122, 33. 
61. CRTM. Available online: https://github.com/JCSDA/crtm (accessed on 7 October 2020).

62. Singh, R.; Kumar, P.; Pal, P.K. Assimilation of Oceansat-2-Scatterometer-Derived Surface Winds in the Weather Research and Forecasting Model. IEEE Trans. Geosci. Remote Sens. 2012, 50, 1015-1021. [CrossRef]

63. Yang, C.; Liu, Z.; Bresch, J.; Rizvi, S.; Huang, X.; Min, J. AMSR2 all-sky radiance assimilation and its impact on the analysis and forecast of Hurricane Sandy with a limited-area data assimilation system. Tellus A Dyn. Meteorol. Oceanogr. 2016, 68, 30917. [CrossRef]

64. Xian, Z.; Chen, K.; Zhu, J. All-sky assimilation of the MWHS-2 observations and evaluation the impacts on the analyses and forecasts of binary typhoons. J. Geophys. Res. Atmos. 2019, 124, 6359-6378. [CrossRef]

65. Wang, C.C. On the calculation and correction of equitable threat score for model quantitative precipitation forecasts for small verification areas: The example of Taiwan. Weather Forecast. 2014, 29, 788-798. [CrossRef]

66. Paulat, M.; Wernli, H.; Hagen, M.; Frei, C. SAL-A Novel Quality Measure for the Verification of Quantitative Precipitation Forecasts. Mon. Weather Rev. 2008, 136, 4470-4487. 